\title{
Gallium Nitride (GaN) Nanostructures and Their Gas Sensing Properties: A Review
}

\author{
Md Ashfaque Hossain Khan * (1) and Mulpuri V. Rao \\ Department of Electrical and Computer Engineering, George Mason University, Fairfax, VA 22030, USA; \\ rmulpuri@gmu.edu \\ * Correspondence: mkhan53@gmu.edu
}

Received: 4 June 2020; Accepted: 10 July 2020; Published: 13 July 2020

\begin{abstract}
In the last two decades, GaN nanostructures of various forms like nanowires (NWs), nanotubes (NTs), nanofibers (NFs), nanoparticles (NPs) and nanonetworks (NNs) have been reported for gas sensing applications. In this paper, we have reviewed our group's work and the works published by other groups on the advances in $\mathrm{GaN}$ nanostructures-based sensors for detection of gases such as hydrogen $\left(\mathrm{H}_{2}\right)$, alcohols $(\mathrm{R}-\mathrm{OH})$, methane $\left(\mathrm{CH}_{4}\right)$, benzene and its derivatives, nitric oxide $(\mathrm{NO})$, nitrogen dioxide $\left(\mathrm{NO}_{2}\right)$, sulfur-dioxide $\left(\mathrm{SO}_{2}\right)$, ammonia $\left(\mathrm{NH}_{3}\right)$, hydrogen sulfide $\left(\mathrm{H}_{2} \mathrm{~S}\right)$ and carbon dioxide $\left(\mathrm{CO}_{2}\right)$. The important sensing performance parameters like limit of detection, response/recovery time and operating temperature for different type of sensors have been summarized and tabulated to provide a thorough performance comparison. A novel metric, the product of response time and limit of detection, has been established, to quantify and compare the overall sensing performance of $\mathrm{GaN}$ nanostructure-based devices reported so far. According to this metric, it was found that the InGaN/GaN NW-based sensor exhibits superior overall sensing performance for $\mathrm{H}_{2}$ gas sensing, whereas the $\mathrm{GaN} /\left(\mathrm{TiO}_{2}-\mathrm{Pt}\right.$ ) nanowire-nanoclusters (NWNCs)-based sensor is better for ethanol sensing. The $\mathrm{GaN} / \mathrm{TiO}_{2} \mathrm{NWNC}$-based sensor is also well suited for TNT sensing. This paper has also reviewed density-functional theory (DFT)-based first principle studies on the interaction between gas molecules and GaN. The implementation of machine learning algorithms on GaN nanostructured sensors and sensor array has been analyzed as well. Finally, gas sensing mechanism on GaN nanostructure-based sensors at room temperature has been discussed.
\end{abstract}

Keywords: gallium nitride (GaN); nanostructure; gas sensing; sensitivity; response/recovery time; density-functional theory (DFT); internet of things (IoT); machine learning (ML)

\section{Introduction}

Despite having many advantages, carbon nanotubes (NTs) still suffer from the uncontrollability of selective growth of semiconducting and metallic NTs [1]. Also, the bandgap of carbon NTs cannot be controlled, hence their chemical reactivity cannot be influenced strongly [2]. Semiconducting nanowires made of compound semiconductors, possess higher flexibility as their bandgaps and doping characteristics can be tuned by manipulating the alloy composition and impurity concentrations, respectively [3]. Compound semiconductors are mainly prepared from the elements in groups II to VI of the periodic table. Several binary and ternary compound semiconductor-based nanostructure devices had been demonstrated earlier [4]. In case of group III-V compounds, each group III atom is attached to four group $\mathrm{V}$ atoms to achieve an octet in the valence band. The valence charge from a group V atom moves toward a group III atom and thus promotes partial ionic bonding to the crystal [5].

Bulk GaN is one of the most explored group III-nitride semiconductor materials, which has been employed in various applications such as optoelectronic devices [6], electronic devices [7], biosensors [8], chemical sensors [9-11] and so on. Since GaN has a direct and wide band gap of $3.4 \mathrm{eV}$ 
at room temperature, it is quite robust. Other group III elements like $\mathrm{Al}$ and In can be alloyed with Ga to tune the bandgap of III-nitrides from $0.8 \mathrm{eV}$ to $6 \mathrm{eV}$ [12-14]. Moreover, it possesses high electron mobility, high heat capacity and high breakdown voltage, which are all useful properties for reliable sensing of gas/chemical molecules [15].

Internet of Things (IoT) applications require ultra-low power, mini-sized chemical sensors, which are easily integrated into electronic circuits for remote air quality monitoring in automated systems [16-18]. Nanostructures are suitable candidates for this type of sensing application. Having a large surface-to-volume ratio, nanostructures such as nanowires, nanorods, nanotubes, nanoparticles and nanobelts favor adsorption of gas molecules on the sensor and thus increase the sensitivity of the device [19-21]. The larger interaction between the gas analytes and the sensing surface allows nanostructures to be employed for high performance gas sensing as opposed to their bulk/microstructure counterparts. Although commercially available metal-oxide nanostructure-based gas sensors show high sensitivity and low detection limits [22], they suffer from issues such as poor analyte selectivity, high operating temperature and unstable performance in harsh environments [23]. $\mathrm{GaN}$ nanostructures offer stable operation under various radiation and in space conditions. They operate at room-temperature and can also tolerate large variations of temperature and humidity as compared to metal-oxides [24]. Thus, GaN nanostructure sensors have the potential to take over a significant share of the gas sensing market.

In the past several years, efforts have been made on GaN nanostructures-based devices to detect various chemical analytes. In this work, we have reviewed our group's work and the works published by other groups on the advances in GaN nanostructures-based sensors for detection of gases such as hydrogen $\left(\mathrm{H}_{2}\right)$, alcohols $(\mathrm{R}-\mathrm{OH})$, methane $\left(\mathrm{CH}_{4}\right)$, benzene and its derivatives, nitric oxide $(\mathrm{NO})$, nitrogen dioxide $\left(\mathrm{NO}_{2}\right)$, sulfur-dioxide $\left(\mathrm{SO}_{2}\right)$, ammonia $\left(\mathrm{NH}_{3}\right)$, hydrogen sulfide $\left(\mathrm{H}_{2} \mathrm{~S}\right)$ and carbon dioxide $\left(\mathrm{CO}_{2}\right)$. The sensing performance parameters like limit of detection, response/recovery time and operating temperature for different types of sensors and structures have been summarized and tabulated to perform the comparative study. A novel metric, the product of response time and limit of detection, has been calculated for each sensor in order to compare the overall sensing performance. Then, DFT studies on molecular models of gas molecules and GaN have been reviewed. Next, photo-assisted gas sensing and machine learning implementation have been discussed. Furthermore, gas sensing mechanisms of the GaN sensors have been discussed to understand the basic interaction between sensor surface and gas molecules.

\section{GaN Nanostructures-Based Gas Sensors}

\subsection{GaN Nanostructures-Based Hydrogen Sensors}

Hydrogen gas is highly inflammable when its concentration exceeds $4 \%$ in air [25]. Detection of $\mathrm{H}_{2}$ leakage from gas pipes and storage systems is thus very important to avoid explosions [26]. GaN NW networks decorated with $\mathrm{Ga}_{2} \mathrm{Pd}_{5}$ nanodots have been demonstrated as a high performance $\mathrm{H}_{2}$ sensor [27]. The $\mathrm{Ga}_{2} \mathrm{Pd}_{5}$ nanodot functionalization enhanced the response by more than 50 -fold compared to that of bare GaN NWs due to two main reasons: chemical sensitization and electronic sensitization mechanisms [28]. The hydrogen spillover effect of $\mathrm{Ga}_{2} \mathrm{Pd}_{5}$ played an important role in this enhancement, where atomic hydrogen is generated through the catalytic dissociation of $\mathrm{H}_{2}$ molecules. The fabricated device was able to detect as low as $100 \mathrm{ppm}$ of $\mathrm{H}_{2}$ gas at room temperature. However, the recovery process of the sensor was quite slow (800 s).

Aluri et al. [29] fabricated $\mathrm{TiO}_{2}$-Pt nanocluster-coated $\mathrm{GaN}$ NW sensor devices. Figure $1 \mathrm{~A}$ shows a HRTEM image of $\mathrm{TiO}_{2}$ sputtered GaN NW after Pt deposition, where titania $\left(\mathrm{TiO}_{2}\right)$ particles exhibits $0.35 \mathrm{~nm}$ fringes corresponding to (101) lattice spacing of the anatase polymorph. The black arrows indicate an amorphized surface film having a thickness of $2-5 \mathrm{~nm}$. The device was able to detect as low as $1 \mathrm{ppm}$ of $\mathrm{H}_{2}$ gas at room temperature with a short response-recovery time $(60 \mathrm{~s} / 45 \mathrm{~s})$ under $\mathrm{UV}$ illumination. Figure $1 \mathrm{~B}$ shows the variation of sensor current of a $\mathrm{GaN} /\left(\mathrm{TiO}_{2}-\mathrm{Pt}\right)$ device for different 
concentrations of $\mathrm{H}_{2}$ in nitrogen. The sensing behavior was mainly attributed to the work-function change of Pt NCs due to hydrogen adsorption [30].

Abdullah et al. [31] reported that $\mathrm{GaN}$ adopts various morphologies under various $\mathrm{NH}_{3}$ gas flow rates at constant temperature $\left(1000{ }^{\circ} \mathrm{C}\right)$ during its chemical vapor deposition (CVD) growth process. GaN was grown as thin films, nanowires and microstructures, respectively, with increasing $\mathrm{NH}_{3}$ flow rate. The nanowires-based sensor exhibited a response of $127 \%$ for $100 \mathrm{ppm} \mathrm{H}_{2}$ gas at room temperature, which is quite high compared to the corresponding microstructures-based sensor. The high surface area of the GaN NWs facilitated this sensor performance enhancement. Paul et al. [32] developed Pt-film decorated InGaN/GaN NWs for $\mathrm{H}_{2}$ detection. The sensor was able to detect as low as $200 \mathrm{ppb}$ of $\mathrm{H}_{2}$ at $80^{\circ} \mathrm{C}$ with a fast response-recovery process $(1 \mathrm{~min} / 1 \mathrm{~min})$. In another study, GaN NWs coated with $\mathrm{Pt}$ were employed for ppm level detection of $\mathrm{H}_{2}$ at room temperature [33]. It was found that response-recovery process of the sensor became faster with increasing operating temperature. Also, it was reported that the GaN nanowires co-decorated with $\mathrm{Au}$ and Pt nanoparticles show much stronger response to $\mathrm{H}_{2}$ gas than the $\mathrm{Au}$ or Pt monometal-decorated counterparts [34].

Beside nanowire-based sensors, other GaN nanostructures such as nanotube-, nanonetwork-, and nanoparticle-based $\mathrm{H}_{2}$ sensors have been explored as well. Sahoo et al. [35] synthesized wurtzite structured $\mathrm{GaN}$ nanotubes utilizing a quasi-vapor-solid process to detect $\mathrm{H}_{2}$ gas at room temperature. Pt nanoclusters were incorporated onto the nanotubes in order to enhance the sensitivity. The nanotube-based sensor was able to detect as low as $25 \mathrm{ppm}$ of $\mathrm{H}_{2}$ with a small activation energy of $29.4 \mathrm{meV}$. In another work, a Pd coating was used to functionalize a network of GaN NWs for $\mathrm{H}_{2}$ sensing [36]. The as-grown GaN nanowire network is shown in Figure 1C. On exposure to different $\mathrm{H}_{2}$ concentrations at room temperature, the Pd-coated and uncoated GaN NW network sensors exhibited a clear contrast in response, as illustrated in Figure 1D. Pd has the capability to split hydrogen molecule into atoms, thus it contributes to the better sensor response.

(A)

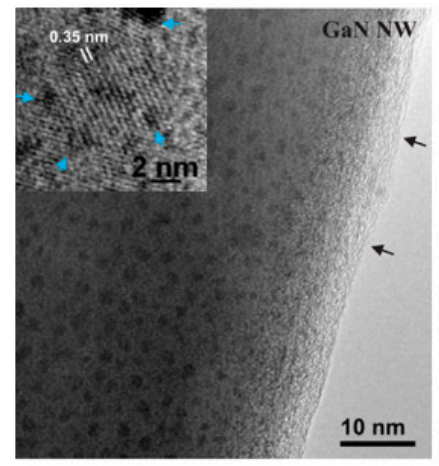

(c)

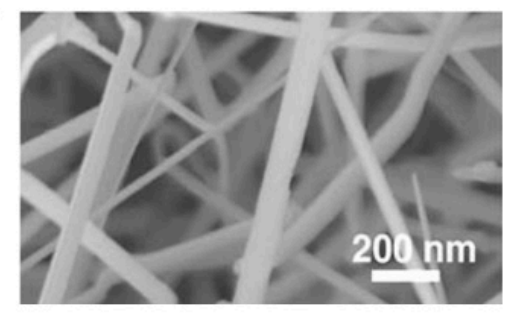

(B)
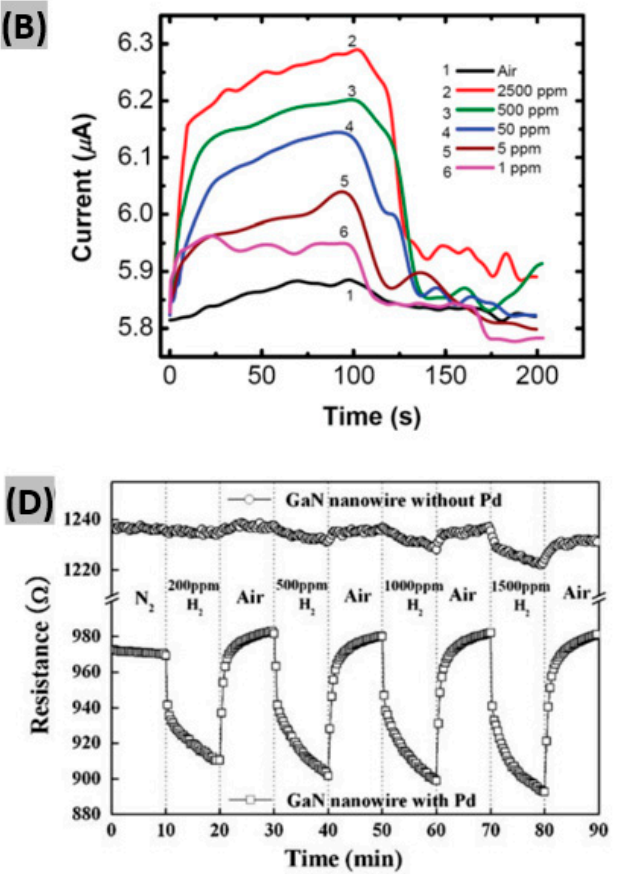

Figure 1. (A) HRTEM image of $\mathrm{TiO}_{2}$ sputtered GaN NW after Pt deposition. Inset shows a magnified image where blue arrows indicate Pt clusters deposited on $\mathrm{TiO}_{2}$. (B) Variation of sensor current of $\mathrm{GaN} /\left(\mathrm{TiO}_{2}-\mathrm{Pt}\right)$ device toward various concentrations of $\mathrm{H}_{2}$ in nitrogen. Figures adapted with permission from [29], Copyright 2012 IOP Publishing Ltd. (C) Scanning electron microscopy (SEM) micrographs of as-grown nanowires. (D) Resistance responses of Pd-coated and uncoated GaN NW at the exposure of $\mathrm{H}_{2}$ concentrations ranging from $200 \mathrm{ppm}$ to $1500 \mathrm{ppm}$. Figures adapted with permission from [36], Copyright 2008 TMS. 
In another study, a lightly Mg-doped porous GaN nanonetwork had been synthesized by a molecular beam epitaxy method [37]. Pt was deposited on a honeycomb nanonetwork by sputtering to form a network containing nano-Schottky contacts. The developed sensor was able to detect as low as $320 \mathrm{ppm}$ of $\mathrm{H}_{2}$ gas at room temperature with a short response time (1 $\left.\mathrm{min}\right)$. However, the recovery process of the sensor was quite slow $(8 \mathrm{~min})$. Furthermore, a GaN nanoparticles (NPs)-based thick film sensor successfully detected $50 \mathrm{ppm}$ of $\mathrm{H}_{2}$ gas at room temperature with a fast recovery process (70 s) [28].

The GaN nanostructure sensor methods of synthesis and the corresponding sensing performance metrics, including limit of detection, response/recovery times and operating temperatures are summarized in Table 1. It provides a brief comparative performance outline among the different GaN nanostructure-based $\mathrm{H}_{2}$ sensors reported to date.

Table 1. Synthesis and sensing properties of $\mathrm{GaN}$ nanostructures based $\mathrm{H}_{2}$ sensors.

\begin{tabular}{|c|c|c|c|c|c|}
\hline Sensor Type & Method of Synthesis & $\begin{array}{c}\text { Response/Recovery } \\
\text { Times }\end{array}$ & $\begin{array}{c}\text { Lowest Detection } \\
\text { Limit }\end{array}$ & $\begin{array}{l}\text { Operating } \\
\text { Temperature }\end{array}$ & Reference \\
\hline $\begin{array}{c}\mathrm{Ga}_{2} \mathrm{Pd}_{5} \\
\text { Nanodot-GaN NWs }\end{array}$ & $\begin{array}{l}\text { Chemical vapor } \\
\text { deposition }\end{array}$ & $200 / 800 \mathrm{~s}$ & 100 ppm & RT & [27] \\
\hline $\begin{array}{l}\mathrm{GaN} /\left(\mathrm{TiO}_{2}-\mathrm{Pt}\right) \\
\mathrm{NWNC}\end{array}$ & $\begin{array}{l}\text { Catalyst-free molecular } \\
\text { beam epitaxy }\end{array}$ & $60 / 45 \mathrm{~s}$ & $1 \mathrm{ppm}$ & RT (UV) & [29] \\
\hline GaN NWs & $\begin{array}{l}\text { Chemical vapor } \\
\text { deposition }\end{array}$ & $103 / 82 \mathrm{~s}$ & 7 ppm & RT & [31] \\
\hline InGaN/GaN NWs & $\begin{array}{l}\text { Plasma-assisted } \\
\text { molecular beam epitaxy }\end{array}$ & $\begin{array}{c}1 / 1 \mathrm{~min} \\
10 / 10 \mathrm{~min}\end{array}$ & $\begin{array}{l}200 \mathrm{ppb} \\
10 \mathrm{ppm}\end{array}$ & $\begin{array}{c}80{ }^{\circ} \mathrm{C} \\
\mathrm{RT}\end{array}$ & {$[32]$} \\
\hline Pt-GaN NWs & $\begin{array}{l}\text { Chemical vapor } \\
\text { deposition }\end{array}$ & $500 \mathrm{~s} / 120 \mathrm{~s}$ & 200 ppm & RT & [33] \\
\hline Pt-GaN NTs & $\begin{array}{l}\text { Chemical vapor } \\
\text { deposition }\end{array}$ & $120 \mathrm{~s} / 5 \mathrm{~min}$ & $25 \mathrm{ppm}$ & $100^{\circ} \mathrm{C}$ & [35] \\
\hline Pd-GaN NWs & $\begin{array}{l}\text { Catalytic chemical vapor } \\
\text { deposition (CVD) }\end{array}$ & $5 / 2 \min$ & 200 ppm & RT & [36] \\
\hline $\begin{array}{c}\mathrm{Pt} / \text { porous GaN } \\
\text { nanonetwork }\end{array}$ & Molecular beam epitaxy & $1 / 8 \mathrm{~min}$ & 320 ppm & RT & [37] \\
\hline GaN NPs & $\begin{array}{l}\text { Solvothermal } \\
\text { decomposition }\end{array}$ & $110 / 70 \mathrm{~s}$ & $50 \mathrm{ppm}$ & RT & [38] \\
\hline Pd-GaN NWs & $\begin{array}{l}\text { Thermal chemical vapor } \\
\text { deposition }\end{array}$ & $300 / 120 \mathrm{~s}$ & 200 ppm & RT & [39] \\
\hline GaN NWs & Two step CVD & $100 / 120 \mathrm{~s}$ & $200 \mathrm{ppm}$ & RT & [40] \\
\hline $\begin{array}{l}\text { Porous } \mathrm{GaN} \text { on } \mathrm{Si} \\
\qquad\left(\begin{array}{lll}1 & 1 & 1\end{array}\right)\end{array}$ & $\begin{array}{l}\text { Plasma-assisted } \\
\text { molecular beam epitaxy }\end{array}$ & $3 / 2.5 \mathrm{~min}$ & $1 \mathrm{sccm}$ & RT & [41] \\
\hline $\begin{array}{l}\text { Honeycomb GaN } \\
\text { nanonetwork }\end{array}$ & Molecular beam epitaxy & $\begin{array}{l}13.2 /-\mathrm{s} \\
4.4 /-\mathrm{s}\end{array}$ & 50 ppm & $\begin{array}{c}30^{\circ} \mathrm{C} \\
100^{\circ} \mathrm{C}\end{array}$ & [42] \\
\hline
\end{tabular}

\subsection{GaN Nanostructures-Based Alcohol Sensors}

Because more than a certain amount of alcohol exposure is detrimental to health, the precise detection of ambient alcohol particles is necessary. For example, methanol can poison the human central nervous system with a median lethal dose of $100 \mathrm{~mL}$ [43]. Ji et al. incorporated GaN nanograins on a silicon nanoporous pillar array (Si-NPA) by the CVD technique for methanol detection [44]. The fabricated device was able to detect as low as $5 \mathrm{ppm}$ of methanol with a fast response-recovery process due to a large surface area and numerous surface-active sites. The optimum temperature for the best sensor response was found to be $350{ }^{\circ} \mathrm{C}$.

Luo et al. [45] reported a comparative study on ethanol sensing performance between GaN nanofibers (NFs) and GaN nanoparticles (NPs). Because GaN-NFs provide porous structures, large specific surface areas and crosslinking properties, they show a better sensing response to ethanol [46]. The optimum working temperature found for both types of sensors was $320{ }^{\circ} \mathrm{C}$. The synthesized sensors were capable of detecting $50 \mathrm{ppm}$ of ethanol with a very fast response-recovery 
process ( $8 \mathrm{~s} / 5 \mathrm{~s})$. Moreover, the GaN-NFs-based sensor responded more quickly to ethanol than GaN-NPs-based sensor due to the fast diffusion capability of its porous nanostructures.

The alcohol sensing properties of GaN NWs grown on $\mathrm{Si}\left(\begin{array}{lll}1 & 1 & 1\end{array}\right)$ substrates and functionalized with tin dioxide $\left(\mathrm{SnO}_{2}\right)$ nanoparticles had been demonstrated by Bajpai et al. [47]. This chemiresistive sensor successfully detected alcohol vapors, including methanol, ethanol, propanol and butanol, at concentrations as low as $1 \mathrm{ppm}$ at room temperature under UV excitation. It was found that resistive response decreases with the increasing carbon chain for aliphatic alcohols, as shown in Figure 2A. Also, the sensor response was diminished in the case of isomeric branching. Alcohols can remove adsorbed oxygen to release free electrons on $\mathrm{SnO}_{2}$, which promotes the rise of the photoconductivity in GaN NWs. This phenomenon contributed to achieve high sensitivity to alcohol vapors with a reasonable response-recovery time (200 s/100 s).

Aluri et al. [29] fabricated $\mathrm{TiO}_{2}-\mathrm{Pt}$ nanocluster-coated $\mathrm{GaN} \mathrm{NW}$ sensor devices using a catalyst-free molecular beam epitaxy growth process. They reported that $\mathrm{TiO}_{2}-\mathrm{Pt}$ nanocluster-coated $\mathrm{GaN} \mathrm{NW}$ hybrid sensor devices are able to detect as low as $100 \mathrm{ppb}$ of ethanol and $0.5 \mathrm{ppm}$ of methanol at room temperature under UV illumination with a short response-recovery time ( $80 \mathrm{~s} / 60-80 \mathrm{~s})$. They explained the alcohol selectivity of the sensor in terms of heat of adsorption, ionization energy and solvent polarity. In another work [28], a GaN NPs-based thick film sensor was able to detect $50 \mathrm{ppm}$ of ethanol at room temperature with a fast response-recovery process (50 s/30 s). Recently, porous GaN nanorods were prepared by a hydrothermal method by Zhang et al. [48]. Gas-sensing measurements indicated that the porous sensor exhibits high sensitivity and strong selectivity to ethanol, and good stability at high temperature $\left(360^{\circ} \mathrm{C}\right)$. They presented a new route for the synthesis of $\mathrm{GaN}$ submicron rods [49]. The enhanced sensing performance toward ethanol is attributed to the large specific surface area, small grain size, and high length-to-diameter ratio of the developed GaN submicron rods.

The GaN nanostructured sensor synthesis method and corresponding sensing performance metrics including limit of detection, response/recovery times and operating temperatures are summarized in Table 2. It provides a brief comparative performance outline among different $\mathrm{GaN}$ nanostructure-based alcohol sensors reported in the past.

Table 2. Synthesis and sensing properties of GaN nanostructures-based alcohol sensors.

\begin{tabular}{|c|c|c|c|c|c|c|}
\hline Sensor Type & $\begin{array}{l}\text { Target } \\
\text { Analyte }\end{array}$ & Synthesis Method & $\begin{array}{c}\text { Response/Recovery } \\
\text { Times }\end{array}$ & $\begin{array}{c}\text { Lowest } \\
\text { Detection Limit }\end{array}$ & $\begin{array}{l}\text { Operating } \\
\text { Temperature }\end{array}$ & Reference \\
\hline $\begin{array}{c}\mathrm{GaN} /\left(\mathrm{TiO}_{2}-\mathrm{Pt}\right) \\
\mathrm{NWNC}\end{array}$ & Ethanol & $\begin{array}{c}\text { Catalyst-free molecular } \\
\text { beam epitaxy }\end{array}$ & $80 / 60 \mathrm{~s}$ & $100 \mathrm{ppb}$ & RT (UV) & [29] \\
\hline $\begin{array}{c}\mathrm{GaN} /\left(\mathrm{TiO}_{2}-\mathrm{Pt}\right) \\
\mathrm{NWNC}\end{array}$ & Methanol & $\begin{array}{l}\text { Catalyst-free molecular } \\
\text { beam epitaxy }\end{array}$ & $80 / 80 \mathrm{~s}$ & $0.5 \mathrm{ppm}$ & RT (UV) & [29] \\
\hline GaN NPs & Ethanol & $\begin{array}{l}\text { Solvothermal } \\
\text { decomposition }\end{array}$ & $50 / 30 \mathrm{~s}$ & $50 \mathrm{ppm}$ & RT & [38] \\
\hline $\begin{array}{l}\text { GaN/Si- nanoporous } \\
\text { pillar array (NPA) }\end{array}$ & Methanol & $\begin{array}{l}\text { Chemical vapor } \\
\text { deposition }\end{array}$ & $8 / 7 \mathrm{~s}$ & $5 \mathrm{ppm}$ & $350^{\circ} \mathrm{C}$ & [44] \\
\hline Porous GaN-NFs & Ethanol & Electrospinning & $8 / 5 \mathrm{~s}$ & 50 ppm & $320^{\circ} \mathrm{C}$ & [45] \\
\hline $\mathrm{SnO}_{2} / \mathrm{GaN} \mathrm{NW}$ & $\begin{array}{l}\text { Alcohol } \\
\text { vapors }\end{array}$ & $\begin{array}{c}\text { Catalyst-free molecular } \\
\text { beam epitaxy }\end{array}$ & $200 / 100 \mathrm{~s}$ & $1 \mathrm{ppm}$ & RT (UV) & [47] \\
\hline
\end{tabular}

\subsection{GaN Nanostructures-Based Methane Sensors}

Having a lower explosion limit of 5.0\%, methane detection is highly required in both the household and industrial arena [50]. Patsha et al. employed a CVD method in a vapor-liquid-solid process to make GaN NWs [51]. They introduced different amounts of oxygen in the NWs with varying oxygen impurity concentrations $\left(10^{5} \mathrm{ppm}, 10^{3} \mathrm{ppm}, 10^{2} \mathrm{ppm}\right.$ and $\left.<2 \mathrm{ppm}\right)$ in order to investigate the role of surface defects formed by the oxygen impurities in methane sensing. It was found that sensing response gradually decreases with the decrease of oxygen concentration in the GaN NWs. The prepared sensors were able to detect as low as $50 \mathrm{ppm}$ of methane at $125^{\circ} \mathrm{C}$ with moderate response-recovery 
time (90 s/100 s), as shown in Figure 2B. Also, it was observed that sensor response increases with the increase of temperature, which confirms the chemisorption instead of physisorption of $\mathrm{CH}_{4} \mathrm{molecules}$ on the GaN nanowire surface [52]. The activation energy required for the chemisorption to occur during gas sensing is provided by the temperature rise.
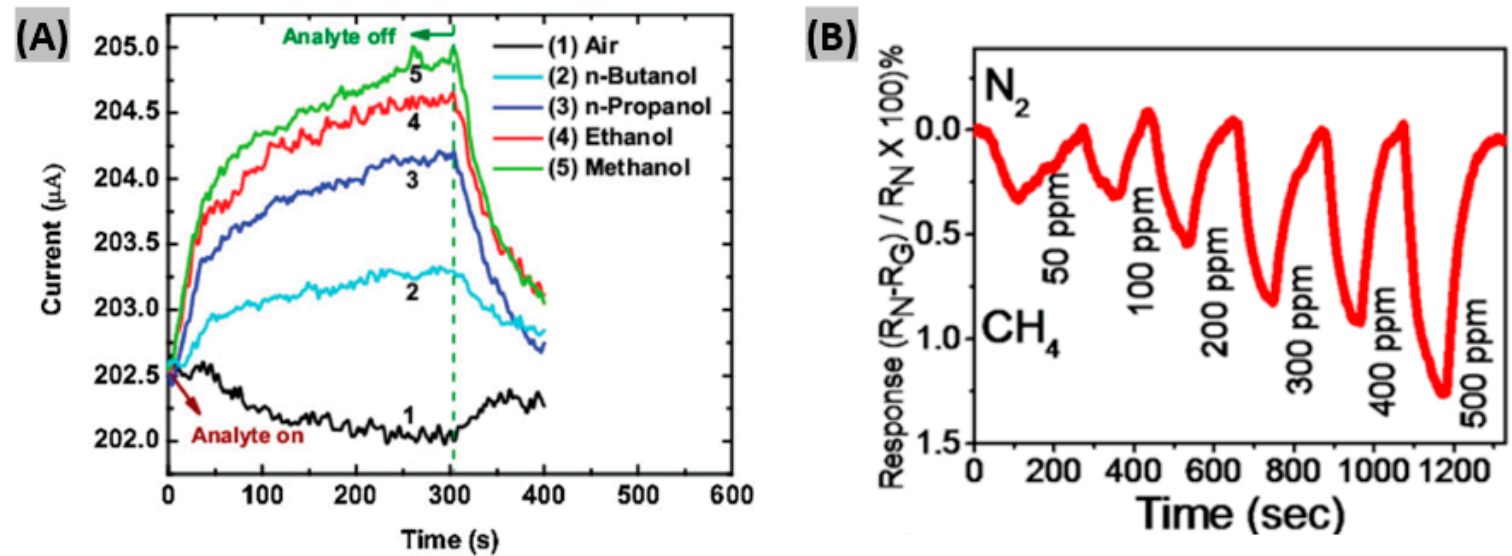

Figure 2. (A) Variation of sensor currents of the $\mathrm{SnO}_{2}$ functionalized GaN NW device toward 500 ppm of various alcohols. Figure adapted with permission from [47], Copyright 2012 Elsevier. (B) Sensor responses of $\mathrm{GaN} \mathrm{NW}$ at the exposure of $\mathrm{CH}_{4}$ gas concentrations ranging from $50 \mathrm{ppm}$ to $500 \mathrm{ppm}$. Figure adapted with permission from [51], Copyright 2015 American Chemical Society.

Popa et al. [53] performed photo-electro-chemical (PEC) etching of GaN layers in a KOH solution and obtained pyramidal GaN layer structures. This sensor was able to detect $1 \%$ of methane gas at an operating temperature of $200{ }^{\circ} \mathrm{C}$ with a rapid response-recovery process $(10 \mathrm{~s} / 60 \mathrm{~s})$. Moreover, it was found that PEC etching in a $\mathrm{H}_{3} \mathrm{PO}_{4}$-based solution facilitates nanoneedle structure formation and exhibits good sensing performance towards alcohols. Previously, GaN NWs incorporated with Au NPs had been reported as a promising methane sensor showing large conductivity changes on exposure to the target gas [54].

\subsection{GaN Nanostructures-Based Benzene and Its Derivatives Sensors}

GaN NWs have been functionalized with $\mathrm{TiO}_{2}$ nanoclusters, using RF magnetron sputtering, and employed UV excitation, to detect vapors of aromatic compounds [55]. This hybrid sensor device was able to detect as low as $50 \mathrm{ppb}$ of benzene, toluene, ethylbenzene, xylene and chlorobenzene mixed with air at room temperature. The response and recovery times were quite short $(60 \mathrm{~s} / 75 \mathrm{~s})$ because of the high reactivity of $\mathrm{TiO}_{2}$ nanoclusters. Figure $3 \mathrm{~A}$ shows the variation of sensor current of the $\mathrm{GaN} / \mathrm{TiO}_{2}$ device for 1000 ppm concentration of different aromatic compounds' in the presence of UV light. For reference, the response of the device for air is also shown in the figure.

In another work, the same $\mathrm{GaN} / \mathrm{TiO}_{2}$ hybrid sensor was implemented for the photo-enhanced detection of trinitrotoluene (TNT) and dinitrobenzene (DNB) at room temperature [56]. It detected as little as $500 \mathrm{ppt}$ of TNT in air and DNB down to $10 \mathrm{ppb}$ with a rapid sensor response-recovery process. Figure 3B illustrates the sensitivity profile of the synthesized device in presence of 1 ppm of different aromatics and nitro-aromatics. It is seen that the sensor is strongly selective to TNT against other interfering aromatic compounds. Being strongly electronegative, nitro-aromatics facilitate charge transfer between the adsorbed species on $\mathrm{TiO}_{2} \mathrm{NCs}$ and the nitro groups, which in turn is reflected in sensing response. It was found that electron affinity increases with the increase in the number of nitro-groups bonded to the aromatics and thus the sensitivity is also enhanced. Table 3 provides a brief comparative performance outline among different GaN nanostructures-based methane, benzene and its derivatives sensors reported in the past. 
Table 3. Synthesis method and sensing properties of GaN nanostructures-based methane, benzene and its derivatives sensors.

\begin{tabular}{|c|c|c|c|c|c|c|}
\hline Sensor Type & Target Analyte & Fabrication Technique & $\begin{array}{c}\text { Response/Recovery } \\
\text { Times }\end{array}$ & $\begin{array}{c}\text { Lowest Detection } \\
\text { Limit }\end{array}$ & $\begin{array}{c}\text { Operating } \\
\text { Temperature }\end{array}$ & Reference \\
\hline GaN NWs & Methane & $\begin{array}{l}\text { CVD in vapor-liquid-solid } \\
\text { process }\end{array}$ & $90 / 100 \mathrm{~s}$ & $50 \mathrm{ppm}$ & $125^{\circ} \mathrm{C}$ & [51] \\
\hline $\begin{array}{c}\text { GaN-based } \\
\text { two-sensor array }\end{array}$ & Methane & $\begin{array}{l}\text { Metalorganic CVD with } \\
\text { photoelectron-chemical } \\
\text { etching }\end{array}$ & $10 / 60 \mathrm{~s}$ & $1 \%$ & $200^{\circ} \mathrm{C}$ & [53] \\
\hline $\begin{array}{c}\mathrm{GaN}-\mathrm{TiO}_{2} \text { hybrid } \\
\text { NWNC }\end{array}$ & $\begin{array}{c}\text { Benzene, toluene, } \\
\text { ethylbenzene, xylene and } \\
\text { chlorobenzene }\end{array}$ & $\begin{array}{c}\text { Catalyst-free molecular } \\
\text { beam epitaxy }\end{array}$ & $60 / 75 \mathrm{~s}$ & $50 \mathrm{ppb}$ & RT (UV) & [55] \\
\hline $\mathrm{GaN} / \mathrm{TiO}_{2} \mathrm{NWNC}$ & $\begin{array}{c}\text { TNT } \\
\text { Dinitrobenzene } \\
\text { (DNB) }\end{array}$ & $\begin{array}{c}\text { Catalyst-free molecular } \\
\text { beam epitaxy }\end{array}$ & $30 / 30 \mathrm{~s}$ & $\begin{array}{l}500 \mathrm{ppt} \\
10 \mathrm{ppb}\end{array}$ & RT (UV) & [56] \\
\hline
\end{tabular}



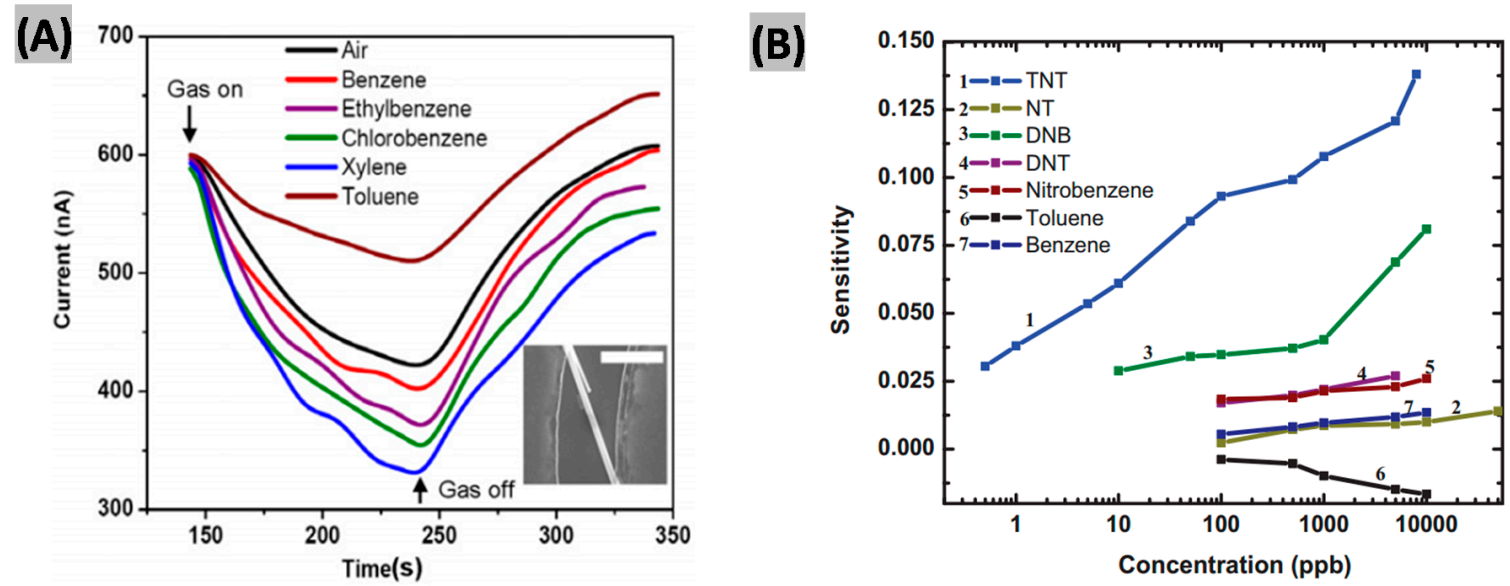

Figure 3. (A) Variation of sensor current of the $\mathrm{GaN} / \mathrm{TiO}_{2}$ device toward $1000 \mathrm{ppm}$ of different aromatic compounds' vapor with a reference of air response in the presence of UV light. Figures adapted with permission from [55], Copyright 2011 IOP Publishing Ltd. (B) Sensitivity profile of the synthesized device in presence of $1 \mathrm{ppm}$ of different aromatics and nitro-aromatics. Figures adapted with permission from [56], Copyright 2013 IEEE.

\subsection{GaN Nanostructures-Based $\mathrm{O}_{2}, \mathrm{O}_{3}, \mathrm{NO}$ and $\mathrm{NO}_{2}$ Sensors}

Although GaN nanostructures have been very suitable for hydrogen and alcohol sensing, detection of various oxidizing gases was also demonstrated. P-i-n GaN nanorods (NRs), comprising of InGaN/GaN multi-quantum wells, have been reported recently for NO gas sensing [57]. This nanorods-based sensor was able to sense as low as $10 \mathrm{ppm}$ of $\mathrm{NO}$ at room temperature. Though the response time was moderate (180 s), the recovery process of the device was too sluggish (400 s) even under UV illumination. Moreover, it was highly selective toward NO gas against other interfering oxidizing gases due to numerous surface states possessed by InGaN NRs.

In another study, GaN nanowires were attached on pencil graphite electrodes using a hydrothermal method for NO detection [58]. The developed sensor allowed a wide detection range of $1.0 \mu \mathrm{M}$ to $1.0 \mathrm{mM}$ with a correlation coefficient of 0.999 and a detection limit of $0.180 \mu \mathrm{M}$, as obtained from cyclic voltammetry and amperometric measurements.

The ppb level detection of $\mathrm{NO}_{2}$ was demonstrated by titania $\left(\mathrm{TiO}_{2}\right)$ nanoclusters-functionalized $\mathrm{GaN}$ submicron wire fabricated by a top-down approach [59]. The $\mathrm{GaN} / \mathrm{TiO}_{2}$ sensor showed a lowest detection limit of $10 \mathrm{ppb}$ of $\mathrm{NO}_{2}$ in air at room temperature $\left(20^{\circ} \mathrm{C}\right)$ (Figure $\left.4 \mathrm{~A}\right)$. The response/recovery (140/160 s) process was quite fast. It exhibited strong selectivity when exposed to $\mathrm{NO}_{2}$ and other interfering gases. Also, the device performance was degraded very little when exposed to siloxane for a one-month period. Previously, Shi et al. [60] fabricated hybrid gas sensors based on $\mathrm{TiO}_{2}$-decorated $\mathrm{GaN}$ nanowires for $\mathrm{NO}_{2}$ detection. The thickness and doping concentration of $\mathrm{TiO}_{2}$ were engineered to improve the transducer function. Results showed that stable n-type response was acquired for a doping range from $10^{17} \mathrm{~cm}^{-3}$ to $10^{19} \mathrm{~cm}^{-3}$. Maier et al. [61] designed an opto-chemical GaN/InGaN NW heterostructure and investigated its photoluminescence response for some oxidizing gases including $\mathrm{O}_{3}, \mathrm{NO}_{2}$, and $\mathrm{O}_{2}$ on it. The sensor system detected $\mathrm{O}_{3}{ }^{-}, \mathrm{NO}_{2}{ }^{-}$, and $\mathrm{O}_{2}{ }^{-}$with a limit of detection (LoD) of $50 \mathrm{ppb}, 500 \mathrm{ppb}$ and $100 \mathrm{ppm}$, respectively at room temperature (Figure 4B-E). Previously, Pt-Pd alloy thin film had been incorporated onto suspended GaN NWs grown by VLS method [62]. The developed sensor exhibited good sensing response toward $\mathrm{NO}_{2}$ at a high operating temperature of $350{ }^{\circ} \mathrm{C}$. The lowest detection limit was estimated as $100 \mathrm{ppm}$, with a reasonable response time. However, the sensor recovery process was slow (>100 s). 

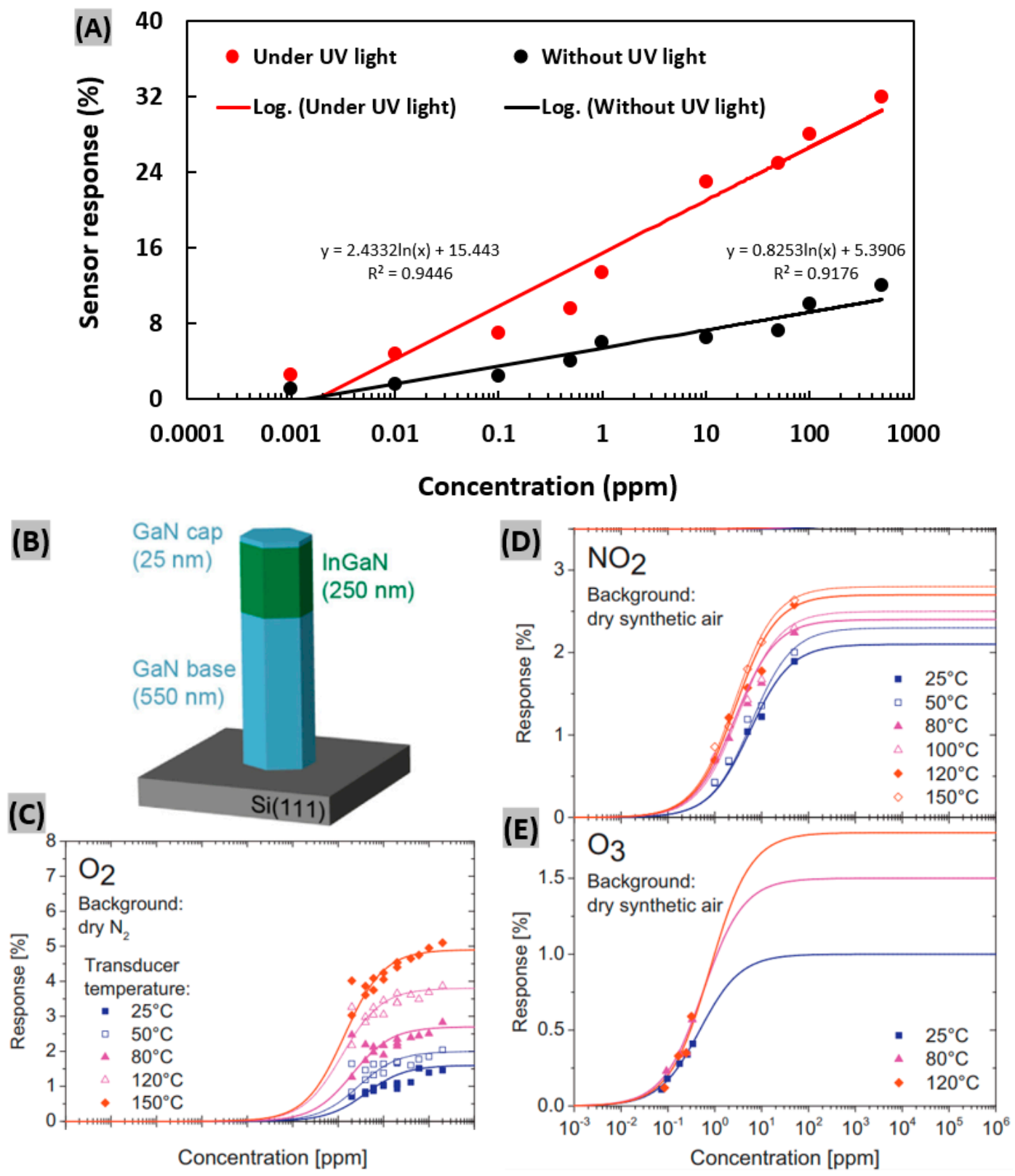

Figure 4. (A) Response fitting curves of the of $\mathrm{GaN} / \mathrm{TiO}{ }_{2} \mathrm{NW}$ sensor to $\mathrm{NO}_{2}$ concentrations ranging from $1 \mathrm{ppb}$ to $500 \mathrm{ppm}$ with UV light and without UV light at room temperature $\left(20^{\circ} \mathrm{C}\right)$. Figure adapted with permission from [59], Copyright 2020 IOP Publishing Ltd. (B) Schematic representation of the $\mathrm{GaN} / \mathrm{InGaN} \mathrm{NW}$ on Si substrate. Variation of (C) $\mathrm{O}_{2}$-response, (D) $\mathrm{NO}_{2}$-response, and (E) $\mathrm{O}_{3}$-response for GaN/InGaN NW sensor with gas concentration and operating temperature. Figures adapted with permission from [61], Copyright 2014 Elsevier.

\subsection{GaN Nanostructures-Based $\mathrm{SO}_{2}, \mathrm{H}_{2} \mathrm{~S}, \mathrm{NH}_{3}$ and $\mathrm{CO}_{2}$ Sensors}

In another work, GaN nanowires were developed on Si substrates using stepper lithography assisted dry-etching in a top-down fabrication approach [63]. The nanowires were functionalized by the deposition of different metal oxides- $\mathrm{ZnO}, \mathrm{WO}_{3}$ and $\mathrm{SnO}_{2}-$ using optimized $\mathrm{RF}$ sputtering. The $\mathrm{ZnO} / \mathrm{GaN}$ sensor was found to be the best candidate for precise $\mathrm{SO}_{2}$ detection as shown in Figure 5A. It showed a response magnitude of $12.1 \%$ at a concentration of $10 \mathrm{ppm}$ of $\mathrm{SO}_{2}$ in air at room temperature $\left(20^{\circ} \mathrm{C}\right)$ with a reasonable response/recovery $(230 / 275 \mathrm{~s})$ period. Additional sensor performance metrics such as adsorption and desorption rate, cross-sensitivity to interfering gases, and long-term stability at various environmental conditions were studied on the $\mathrm{ZnO} / \mathrm{GaN}$ sensor 
device. In addition, the well-known cross-sensitive behavior of $\mathrm{ZnO}$ was resolved using principal component analysis (PCA). Chitara et al. [38] prepared a thick-film sensor based on GaN nanoparticles using a simple chemical route and investigated the sensing properties of $\mathrm{NH}_{3}$ and $\mathrm{H}_{2} \mathrm{~S}$ gases at room-temperature. The variation of sensitivities for $\mathrm{NH}_{3}$ and $\mathrm{H}_{2} \mathrm{~S}$ with the concentration of the vapor is shown in Figure 5B. It was observed that $\mathrm{NH}_{3}$ sensitivity is higher than $50 \%$ for $500 \mathrm{ppm}$. The response and recovery times for $\mathrm{NH}_{3}$ were found to be $200 \mathrm{~s}$ and $90 \mathrm{~s}$, respectively, whereas it was $360 \mathrm{~s}$ and $150 \mathrm{~s}$ for $\mathrm{H}_{2} \mathrm{~S}$.
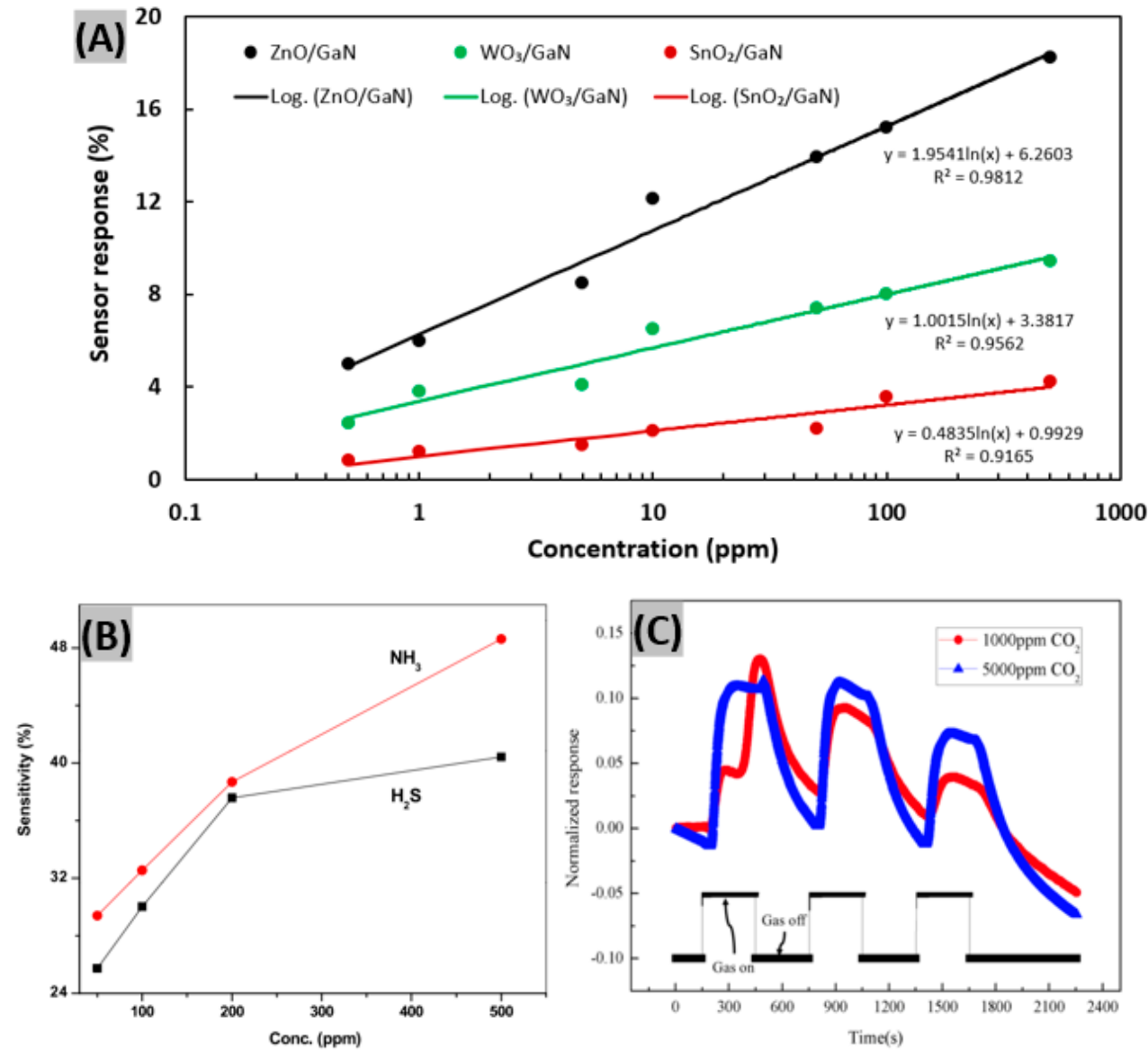

Figure 5. (A) $\mathrm{SO}_{2}$ gas response fitting lines for the $\mathrm{ZnO} / \mathrm{GaN} \mathrm{NW}$ sensor (black), $\mathrm{WO}_{3} / \mathrm{GaN} \mathrm{NW}$ sensor (green) and $\mathrm{SnO}_{2} / \mathrm{GaN} \mathrm{NW}$ sensor (red) under UV light at room temperature $\left(20^{\circ} \mathrm{C}\right)$. Figure adapted with permission from [63], Copyright 2020 Elsevier. (B) The plotting of sensitivity variation of GaN nanoparticles for $\mathrm{H}_{2} \mathrm{~S}$ and $\mathrm{NH}_{3}$ gas at $300 \mathrm{~K}$. Figure adapted with permission from [38], Copyright 2010 Elsevier Ltd. (C) Normalized responses of metal-oxide coated GaN NW sensor device for 1000 and 5000 ppm of $\mathrm{CO}_{2}$ gas under UV light. Figure adapted with permission from [64], Copyright 2018 ICES.

Detection of $\mathrm{CO}_{2}$ gas utilizing metal-oxide-based sensors is challenging due to the chemical inertness and high stability of $\mathrm{CO}_{2}$ at room-temperature. Thomson et al. [64] fabricated GaN submicron wire-based chip-scale, low-power and nanoengineered chemiresistive gas-sensing architecture for $\mathrm{CO}_{2}$ detection. Their design utilized the selective adsorption properties of the nano-photocatalytic clusters of metal-oxides and metals. They achieved better selectivity for $\mathrm{CO}_{2}$ detection in high relative humidity conditions (Figure 5C).

The GaN nanostructured sensor synthesis methods and the corresponding sensing performance metrics, including limit of detection, response/recovery times, and operating temperatures are summarized in Table 4. They provide a brief comparative performance outline among different $\mathrm{GaN}$ nanostructures-based oxidizing and reducing gas sensors reported to date. 
Table 4. Synthesis method and sensing properties of GaN nanostructures-based various oxidizing and reducing gas sensors.

\begin{tabular}{|c|c|c|c|c|c|c|}
\hline Sensor Type & Target Analyte & Fabrication Technique & $\begin{array}{c}\text { Response/Recovery } \\
\text { Times }\end{array}$ & $\begin{array}{c}\text { Lowest Detection } \\
\text { Limit }\end{array}$ & $\begin{array}{c}\text { Operating } \\
\text { Temperature }\end{array}$ & Reference \\
\hline GaN NPs & $\mathrm{NH}_{3}$ & Simple chemical route & $200 / 90 \mathrm{~s}$ & $50 \mathrm{ppm}$ & RT & [38] \\
\hline GaN NPs & $\mathrm{H}_{2} \mathrm{~S}$ & Simple chemical route & $360 / 150 \mathrm{~s}$ & $50 \mathrm{ppm}$ & RT & [38] \\
\hline p-i-n GaN NRs & $\mathrm{NO}$ & $\begin{array}{c}\text { Plasma-assisted molecular } \\
\text { beam epitaxy }\end{array}$ & $180 / 400 \mathrm{~s}$ & $10 \mathrm{ppm}$ & RT (UV) & [57] \\
\hline $\mathrm{GaN} / \mathrm{TiO}_{2} \mathrm{NW}$ & $\mathrm{NO}_{2}$ & $\begin{array}{l}\text { Stepper lithography } \\
\text { assisted ICP etching }\end{array}$ & $140 / 160 \mathrm{~s}$ & $10 \mathrm{ppb}$ & RT (UV) & [59] \\
\hline GaN/InGaN NWs & $\begin{array}{c}\mathrm{O}_{2} \\
\mathrm{NO}_{2} \\
\mathrm{O}_{3} \\
\end{array}$ & $\begin{array}{c}\text { Plasma-assisted molecular } \\
\text { beam epitaxy }\end{array}$ & $-/-$ & $\begin{array}{c}100 \mathrm{ppm} \\
500 \mathrm{ppb} \\
50 \mathrm{ppb}\end{array}$ & RT & [61] \\
\hline $\mathrm{Pt}-\mathrm{Pd} / \mathrm{GaN}$ NWs & $\mathrm{NO}_{2}$ & $\begin{array}{l}\text { Vapor-liquid-solid (VLS) } \\
\text { process }\end{array}$ & $100 />100 \mathrm{~s}$ & $100 \mathrm{ppm}$ & $350^{\circ} \mathrm{C}$ & [62] \\
\hline GaN/ZnO NW & $\mathrm{SO}_{2}$ & $\begin{array}{l}\text { Stepper lithography } \\
\text { assisted ICP etching }\end{array}$ & $230 / 275 \mathrm{~s}$ & $10 \mathrm{ppm}$ & RT (UV) & [63] \\
\hline GaN/Metal-oxide NW & $\mathrm{CO}_{2}$ & ICP etching & $100 / 300 \mathrm{~s}$ & 1000 ppm & RT (UV) & [64] \\
\hline
\end{tabular}




\section{Evaluation of Overall Sensor Performance}

In order to be useful in real world applications, gas/chemical sensors need to possess strong response magnitude, fast response-recovery, excellent selectivity, long operating life and stable device performance. Unfortunately, a gas sensor with all these sensing properties has not been developed yet. In general, while some sensors show very high response magnitudes, their response-recovery processes are however quite slow. Some of them are promising in many aspects but not adaptive to large scale production. There is need for a common scale that we can use to compare the reported sensors to screen out optimal sensor devices. In this work, a novel metric, the product of response time and limit of detection, has been calculated for each sensor in order to quantify and compare the overall sensing performance of reported GaN nanostructures-based devices. The lower the value of the calculated metric, the faster the sensor is with a reasonable detection limit, which means it possesses better overall sensor performance. The obtained values of the proposed metric for different types of GaN nanostructures-based sensors are illustrated in Figure 6.
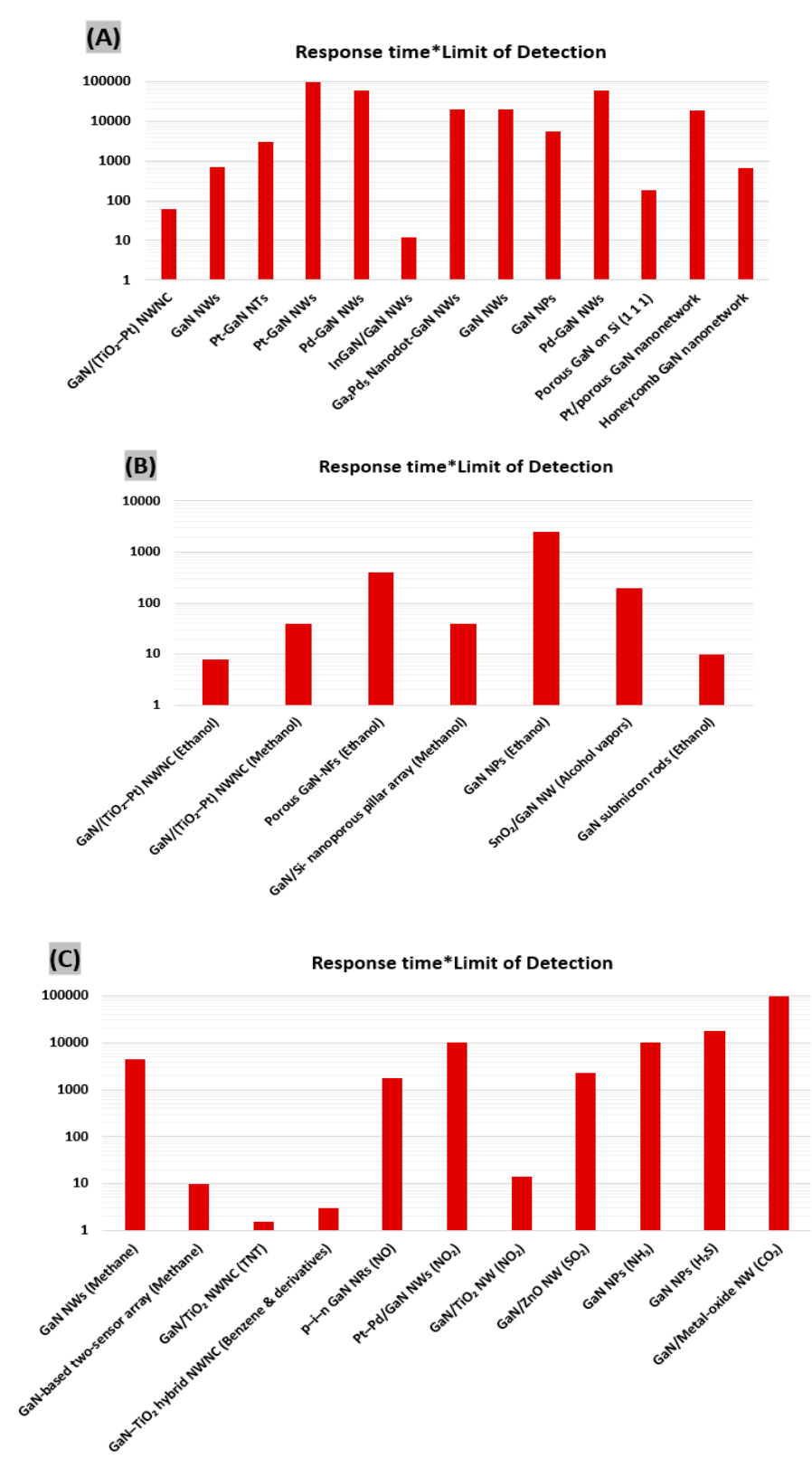

Figure 6. Comparison of the product of response time and limit of detection value among previously reported $\mathrm{GaN}$ nanostructures-based sensors for $(\mathbf{A}) \mathrm{H}_{2},(\mathbf{B})$ alcohols, and $(\mathbf{C})$ other gases. 
It is found that the InGaN/GaN NWs-based sensor exhibits the lowest multiplication value for $\mathrm{H}_{2}$ gas sensing (Figure $6 \mathrm{~A}$ ), whereas $\mathrm{GaN} /\left(\mathrm{TiO}_{2}-\mathrm{Pt}\right.$ ) $\mathrm{NWNC}$-based sensor shows the lowest value for ethanol sensing (Figure 6B). Also, it turns out that $\mathrm{GaN} / \mathrm{TiO}_{2} \mathrm{NWNC}$ is well suited for TNT sensing, as shown in Figure 6C. The more sensors taken in the comparison, the more accurate the suggestion of the optimal sensor will be.

\section{Photo-Assisted Gas Sensing with GaN Nanostructures}

Generally, heated MEMS sensors require power in the $\mathrm{mW}$ range for operation [65]. For irradiating nanostructure-based sensors, the typical power consumed by a UV diode is in $\mu \mathrm{W}$ range, which is quite low as compared to that of heated sensors [66]. Photo-enabled sensing makes it possible to operate gas sensors at room-temperature, resulting in a significant reduction in operating power demand. Typically, metal oxide-based gas sensors are operated at elevated temperatures in order to enhance their surface reactivity through a redox reaction [67]. GaN nanostructures with surface functionalization have the ability to incorporate photo-assisted gas sensing [68]. When UV light is illuminated with a greater energy than $\mathrm{GaN}$ and metal oxide bandgaps, electron-hole pairs are generated in them. Holes diffuse toward the GaN surface because of surface band bending. Thus, carrier lifetime and photocurrent increase within the GaN. The dynamic active adsorption sites are generated on the sensor surface through photo-desorption, which allows the sensors to achieve room temperature gas sensing. In another study, it was observed that the photogenerated electrons facilitate oxygen adsorption and produce the photoinduced oxygen ions [69]. These ions contribute to the room-temperature gas detection and enhanced sensor performance. In addition, UV light improves sensor response and recovery rate along with sensitivity. The wavelength and intensity of UV light had been found to have an impact on the adsorption/desorption kinetics of gas molecules [70]. Photo-assisted sensing also helps to withdraw the residual gas molecules that build up with each exposure. Thus, the absorption sites are fully recovered, and the sensor is able to return to its original baseline resistance.

\section{Machine Learning Algorithms on GaN Nanostructured Sensors}

Machine learning has proven to be an excellent method of data classification and processing. Learning algorithms are suitable for classifying and calibrating gas sensors based on the measurement data received from the sensors. Recently, a gas sensor array was reported comprising of GaN nanowires functionalized with metal incorporated $\mathrm{TiO}_{2}$ and $\mathrm{ZnO}$, as displayed in Figure 7A [71]. The sensor array was tested with $\mathrm{NO}_{2}$, ethanol, $\mathrm{SO}_{2}$ and $\mathrm{H}_{2}$ in presence of $\mathrm{H}_{2} \mathrm{O}$ and $\mathrm{O}_{2}$ gases in both unmixed and mixed conditions at room temperature. Gas analytes leave footprints on the array, which are analyzed to identify the cross-sensitive gases. Various supervised machine learning algorithms including decision tree, support vector machine, naive Bayes and k-nearest neighbor were trained and tested for the classification of gas type. It is seen from the results that the support vector machine and naive Bayes classifiers show better classification accuracy than all other models. Furthermore, unsupervised principal component analysis (PCA) was utilized on the response patterns obtained from the array. Results indicate that all the individual gases form discrete clusters in the score plot, exhibiting an enhanced analyte selectivity (Figure 7B).

Non-linearity is observed in the gas responses when gases remain in mixed conditions [72]. Artificial neural networks (ANNs) have been highly efficient to capture the non-linear response pattern of gas mixtures. In another study, various artificial neural network (ANN) algorithms were trained and tested for the identification and quantification of gas mixtures based on GaN nanowires [73]. A back-propagation neural network model was found to be the optimal classifier among all the considered ANN algorithms based on the statistical and computational complexity results. Furthermore, concentrations of the labelled gases had been predicted in ppm based on the optimal model. 
(A)

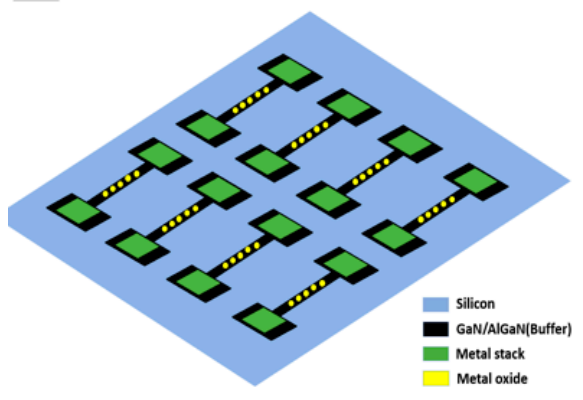

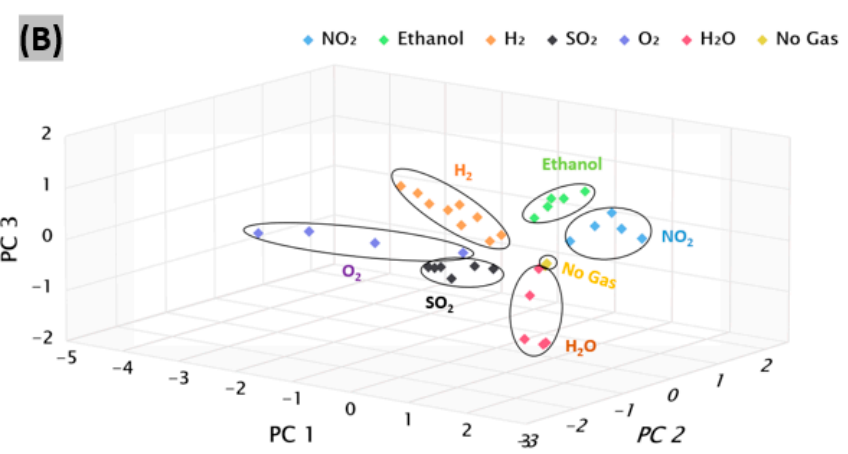

Figure 7. (A) The schematic representation of a sensor array comprising of eight metal/metal-oxide coated GaN NWs. (B) Score plot from principal component analysis (PCA) analysis for various concentrations of $\mathrm{NO}_{2}$, ethanol, $\mathrm{SO}_{2}, \mathrm{H}_{2}, \mathrm{O}_{2}$ and $\mathrm{H}_{2} \mathrm{O}$, which includes up to $95.1 \%$ of the total variance. Figures adapted with permission from [71], Copyright 2020 IEEE.

\section{Molecular Simulation of GaN-Based Gas Sensors}

Several efforts have been made to investigate the adsorption properties of GaN toward different chemical and gas molecules by first-principle method calculations using density functional theory (DFT) as shown in Table 5. Yong et al. [74] studied the adsorption of gas molecules such as- $\mathrm{SO}_{2}$, $\mathrm{NO}_{2}, \mathrm{HCN}, \mathrm{NH}_{3}, \mathrm{H}_{2} \mathrm{~S}, \mathrm{H}_{2}, \mathrm{CO}_{2}, \mathrm{H}_{2} \mathrm{O}$ on the graphitic $\mathrm{GaN}$ sheet (PL-GaN). Results indicated that $\mathrm{SO}_{2}$ and $\mathrm{NH}_{3}$ gas molecules were chemisorbed on the PL-GaN sheet and strong modifications in electronic structures were observed after their adsorption (Figure 8). The local DOS of gas molecules are presented by the dark yellow filled area under the DOS curve. The positive and negative DOS values indicate spin-up and spin-down states, respectively. Furthermore, the adsorption of NO and $\mathrm{NO}_{2}$ molecules introduced spin polarization in the PL-GaN sheet, indicating that it can be employed as a magnetic gas sensor for $\mathrm{NO}$ and $\mathrm{NO}_{2}$ sensing. In another study, adsorption properties such asadsorption energy, adsorption distance, Hirshfeld charge, electronic properties, and recovery time were investigated for $\mathrm{NO}, \mathrm{NH}_{3}$, and $\mathrm{NO}_{2}$ gas molecules on two-dimensional $\mathrm{GaN}$ with a tetragonal structure (T-GaN) [75]. It was found that electronic structures within TGaN exhibited significant changes when $\mathrm{NO}_{2}$ and $\mathrm{NO}$ were adsorbed. On the other hand, electronic structures remained almost unchanged due to $\mathrm{NH}_{3}$ adsorption on TGaN.

Table 5. The adsorption energy (eV), shortest adsorption distance $(\AA)$ and charge transfer (e) between gas molecules and GaN sensors at the most stable adsorption configuration based on DFT.

\begin{tabular}{ccccc}
\hline Materials & Target Gas & Adsorption Energy (eV) & $\begin{array}{c}\text { Shortest Adsorption } \\
\text { Distance (A) }\end{array}$ & Charge Transfer (e) \\
\hline Graphitic GaN sheet [74] & $\mathrm{NO}_{2}$ & -0.493 & 2.44 & -0.081 \\
Graphitic GaN sheet [74] & $\mathrm{SO}_{2}$ & -1.06 & 1.79 & -0.209 \\
Graphitic GaN sheet [74] & $\mathrm{H}_{2} \mathrm{~S}$ & -0.446 & 2.89 & 0.139 \\
2D Tetragonal GaN [75] & $\mathrm{NO}_{2}$ & -0.673 & 2.066 & -0.108 \\
2D Tetragonal GaN [75] & $\mathrm{NH}_{3}$ & -1.317 & 2.089 & 0.289 \\
2D Tetragonal GaN [75] & $\mathrm{NO}$ & -0.872 & 1.374 & -0.271 \\
GaN wurtzoid [76] & $\mathrm{H}_{2}$ & -0.025 & 0.1 & - \\
$\mathrm{TiO}_{2}$ coated GaN [77] & $\mathrm{NO}_{2}$ & -2.31 & 0.25 & 0.214 \\
$\mathrm{ZnO}$ coated GaN [77] & $\mathrm{NO}_{2}$ & -1.96 & 0.30 & 0.187 \\
$\mathrm{SnO}_{2}$ coated GaN [77] & $\mathrm{NO}_{2}$ & -1.95 & & 0.093 \\
\hline
\end{tabular}

It is well known that wurtzoids are bundles of capped $(3,0)$ nanotubes that form the wurtzite phase when they reach nanocrystal or bulk sizes. Abdulsattar et al. [76] performed DFT computations and reported that $\mathrm{GaN}$ wurtzoids as a representative of $\mathrm{GaN}$ nanocrystals are suitable for hydrogen sensing nanostructures. The $\mathrm{N}$ sites were found to be responsible for the $\mathrm{H}$ sensing capability. Ga sites were either strongly bonded to other air gases or have higher interaction energy (Van der Waals' forces) with 
$\mathrm{H}$ molecules that made them highly stable. Furthermore, structural and vibrational properties for bare and hydrogen passivated GaN molecules had been computed and compared with the experimental bulk values.
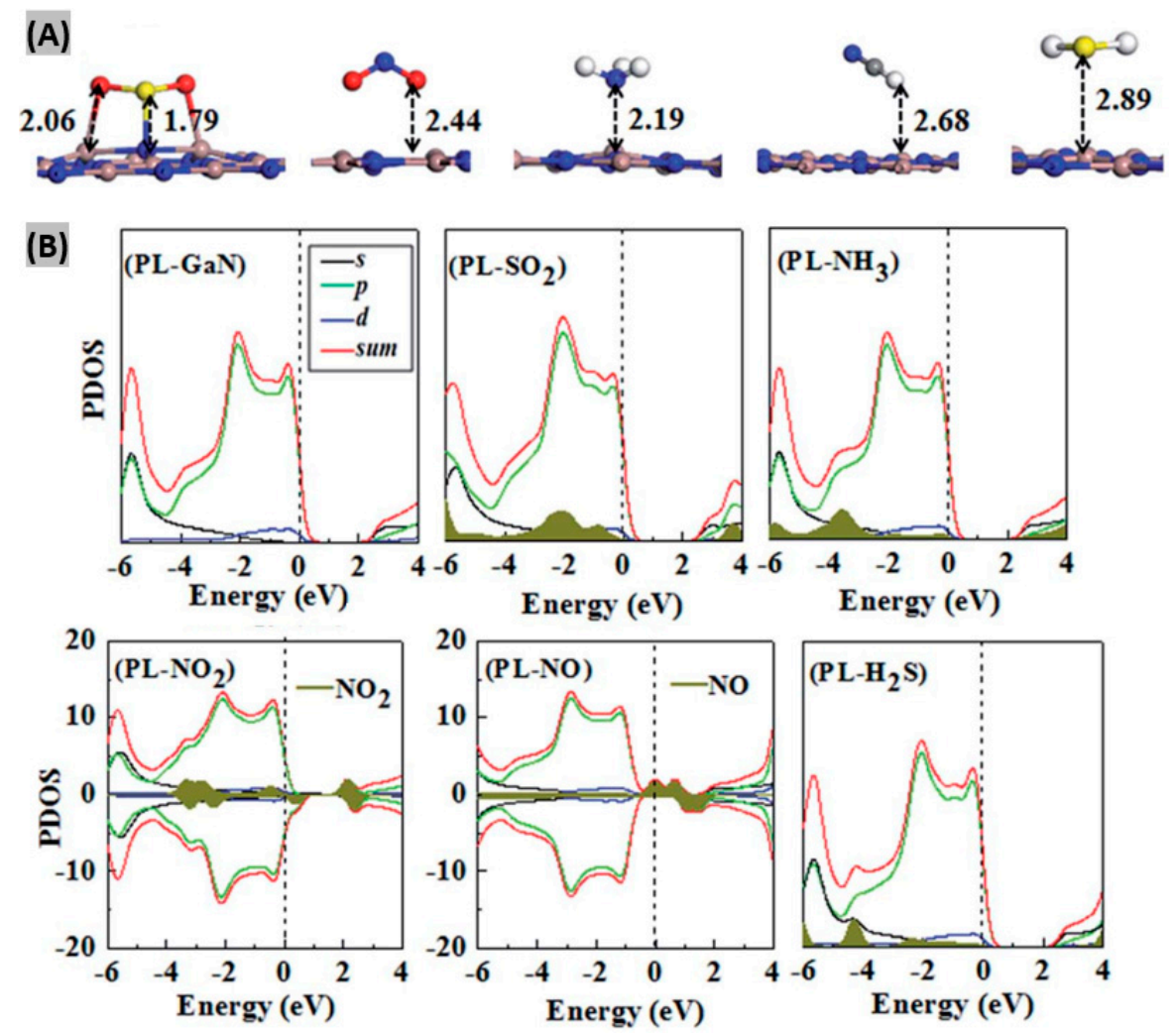

Figure 8. (A) The most stable structures of the PL-GaN sheet with gas molecule adsorption, (From left) $\mathrm{SO}_{2}, \mathrm{NO}_{2}, \mathrm{NH}_{3}, \mathrm{HCN}$ and $\mathrm{H}_{2} \mathrm{~S}$. Adsorption distances are presented in $\AA$. Ga, N, S, O, C and H atoms are brown, blue, yellow, red, grey and white, respectively. (B) Total and partial density of states (DOS) of the most stable structures of the PL-GaN sheet and its adsorption systems with $\mathrm{SO}_{2}, \mathrm{NH}_{3}, \mathrm{NO}_{2}, \mathrm{NO}$, and $\mathrm{H}_{2} \mathrm{~S}$. Fermi-level energy is indicated by vertical dashed line. Figures adapted with permission from [74], Copyright 2017 The Royal Society of Chemistry.

Recently, molecular models of metal oxide-coated GaN nanostructures have been simulated to study their adsorption and electronic properties for gas sensing applications [77,78]. Results indicated that $\mathrm{TiO}_{2}$ functionalization enabled the most energy favorable surface for $\mathrm{NO}_{2}$ adsorption among the considered metal oxides. The total density of states (TDOS) and projected density of states (PDOS) of the nanostructures have been calculated and compared, revealing the nature and strength of chemical interaction between the orbitals of gas molecule and sensor surface. It was also found that recovery of the gas sensing process gets slower because of larger chemical stability of an adsorption system. Therefore, both strong and weak chemical bindings between gas and sensor surface hamper response/recovery speed. The impact of humidity on the adsorbate-sensor interaction has been revealed as well.

\section{Gas Sensing Mechanisms}

It is very important to understand the gas/chemical sensing mechanism of GaN nanostructure-based sensor devices for optimizing the performance of the devices using novel functionalization schemes. The fundamental mechanism responsible for a change in sensor conductivity is the trapping of electrons at adsorbed molecules and band bending induced by these charged molecules [79]. Here, a brief discussion on the sensing mechanism of GaN nanostructured sensors is given for the case of metal-oxide functionalized GaN nanowires at room temperature. Aluri et al. reported that 
electron-hole pairs are generated in both GaN backbone and metal-oxide upon UV illumination [55]. These photogenerated holes in the nanowire tend to diffuse toward the surface due to the surface band bending. The chemisorbed oxygen molecule $\left(\mathrm{O}^{-2}\right)$ and hydroxide ions $\left(\mathrm{OH}^{-}\right)$capture a hole and desorb, creating a surface defect active site as shown in Figure 9A,B. Analyte molecules chemisorb at those active sites and cause surface potential modification of the GaN backbone through dynamic trapping and de-trapping of charge carriers. As a result, the sensor current got modulated in proportion to the analyte concentration. In another work, Zhong et al. [42] investigated the $\mathrm{H}_{2}$ sensing mechanism on $\mathrm{Pt} / \mathrm{GaN}$, where a Schottky barrier is generated between $\mathrm{Pt}$ and $\mathrm{GaN}$ due to the energy difference between their work function and electron affinity (Figure 9C). The analyte $\mathrm{H}_{2}$ molecules are dissociated by the Schottky contact Pt. Then, the chemisorbed $\mathrm{H}$ atoms are diffused to the Pt-GaN interface and absorbed by the absorption sites. Since there is a built-in electric field in the depletion region, dipoles are formed [80]. In consequence, the Schottky barrier height is lowered, contributing to a decrease in Schottky diode voltage. It has been revealed that the magnitude and direction of charge flow rely on the device work function, highest occupied molecular orbital (HOMO), and lowest unoccupied molecular orbital (LUMO). Moreover, chemisorption-induced energy, chemical potentials, electron affinity, and ionization potential have an impact on electron redistribution between the gas molecules and adsorption systems. If the energy difference between Fermi energy and LUMO is much less compared to HOMO, electrons are most likely to transfer to LUMO of the analyte gas. Here, the electrons are transferred from the sensor to the gas molecule by the process of quantum tunneling [81]. As a consequence, the Fermi energy of the device starts going down toward valence band. The charge transfer continues to take place until equilibrium Fermi energy is reached within the adsorption system.

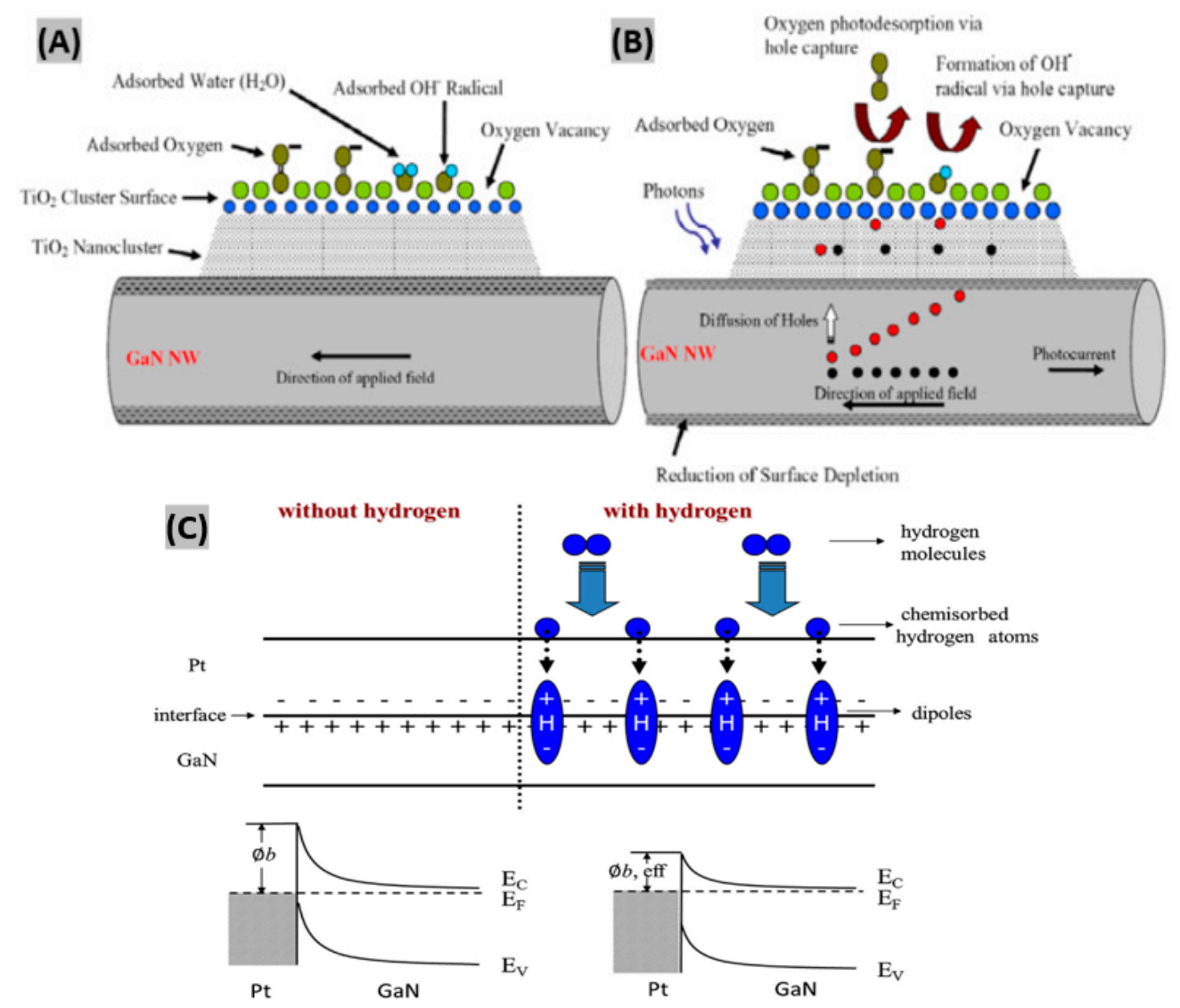

Figure 9. Gas sensing mechanism illustration using schematic representation of the $\mathrm{GaN} / \mathrm{TiO} \mathrm{O}_{2}$ sensor (A) in the dark, and (B) under UV illumination. Figures adapted with permission from [55], Copyright 2011 IOP Publishing Ltd. (C) Sensing mechanism of $\mathrm{H}_{2}$ gas on $\mathrm{GaN} / \mathrm{Pt}$ sensor device. Figure adapted with permission from [42], Copyright 2014 Hydrogen Energy Publications, LLC. Published by Elsevier Ltd. 


\section{GaN Sensors in Internet of Things (IoT) Applications}

It is well known that IoT is a large range of devices that connect to a network and have ability to transfer data to another connected device. IoT devices are required to operate under harsh environmental conditions and exhibit long lifetime [82]. Being chemically robust in nature, semiconducting GaN has the advantages of radiation-tolerance and robustness to environmental temperature variation [83]. It exhibits stable operation across a wide temperature and humidity range. Though GaN shows very little cross-sensitivity toward water vapor [84], its functionalizing material such as metal oxide is cross-sensitive to ambient humidity [85-87]. Therefore, the variation of humidity in real world application causes degradation in sensitivity and selectivity of cross-sensitive sensors. Techniques like sensor array had been employed to enhance the humidity-affected sensor performance through pattern-based sensing [88]. Overall, GaN-based sensors are less cross-sensitive to humidity than the most explored metal oxide-based gas sensors.

GaN-based gas sensors are capable of providing the characteristics required by IoT platforms, thus they are suitable candidate for the IoT applications such as remote air quality monitoring. They can be also incorporated into a multi-purpose field surveillance robot which uses multiple IoT cloud servers [89]. GaN sensors have the capability to be utilized in wireless sensor networks for toxic gas boundary area detection in large-scale petrochemical plants [90]. Furthermore, they can offer high performance sensing in IoT-based vehicle emission monitoring systems [91]. Since GaN sensor devices have the advantages of ultra-low power operation, they can be integrated into embedded-chip or plug-in module as well.

\section{Conclusions and Future Perspectives}

This work reviews and categorizes the progress in $\mathrm{GaN}$ nanostructures-based sensors for detection of gas/chemical species such as hydrogen $\left(\mathrm{H}_{2}\right)$, alcohols $(\mathrm{R}-\mathrm{OH})$, methane $\left(\mathrm{CH}_{4}\right)$, benzene and its derivatives, nitric oxide $(\mathrm{NO})$, nitrogen dioxide $\left(\mathrm{NO}_{2}\right)$, sulfur-dioxide $\left(\mathrm{SO}_{2}\right)$, ammonia $\left(\mathrm{NH}_{3}\right)$, hydrogen sulfide $\left(\mathrm{H}_{2} \mathrm{~S}\right)$ and carbon dioxide $\left(\mathrm{CO}_{2}\right)$. The standard sensing performance parameters like limit of detection, response/recovery time and operating temperature for different types of sensors and structures were summarized comprehensively for the comparative study. The proposed metric, product of response time and limit of detection, has been calculated for each sensor to measure and compare the overall sensing performance among reported $\mathrm{GaN}$ nanostructures-based devices so far. Based on the analysis of sensing characteristics and the proposed metric, it was found that InGaN/GaN NW sensor shows superior overall sensing performance for $\mathrm{H}_{2}$ gas sensing. Also, $\mathrm{GaN} /\left(\mathrm{TiO}_{2}-\mathrm{Pt}\right)$ and $\mathrm{GaN} / \mathrm{TiO}_{2} \mathrm{NWNC}$ sensors are highly suitable for ethanol and TNT sensing, respectively. Moreover, metal-oxide coated $\mathrm{GaN}$ NWs exhibit reliable sensing performance toward various oxidizing gases including $\mathrm{NO}_{2}$ and $\mathrm{SO}_{2}$. Theoretical studies on molecular models of gas molecules and $\mathrm{GaN}$ have been reviewed. Furthermore, a brief analysis of the implementation of machine learning on GaN nanostructured sensors and sensor array has been presented. In addition, gas sensing mechanisms of the GaN sensors have been discussed. This overview on the GaN nanostructures-based gas sensors is helpful for the researchers to gain a quick understanding of the status of GaN nanostructure-based sensors.

There are still many challenges in terms of sensitivity, selectivity, response/recovery speed, and reliability, which need to be addressed to obtain the desired gas sensors. Semiconducting GaN is one of the most promising materials to address these shortcomings in sensing applications. Though most of the reported $\mathrm{GaN}$ nanostructure-based gas sensors show promising performance, research efforts are needed to address important issues like device scalability, reproducibility, and reliability as well. Also, researchers performed their gas sensing experiments in an ideal laboratory condition, which does not simulate real-world environment. Therefore, comprehensive real-world field testing needs to be done for the sensor devices to be effective and long lasting in real world application.

Funding: This research was funded by NSF grant number ECCS1840712. 
Conflicts of Interest: The authors declare no conflict of interest.

\section{References}

1. Harris, P.J.F. Carbon Nanotubes and Related Structures: New Materials for the Twenty-First Century. Am. J. Phys. 2004, 72, 415. [CrossRef]

2. Gu, W.; Yushin, G. Review of nanostructured carbon materials for electrochemical capacitor applications: Advantages and limitations of activated carbon, carbide-derived carbon, zeolite-templated carbon, carbon aerogels, carbon nanotubes, onion-like carbon, and graphene: Nanostructured carbon materials for electrochemical capacitor applications. WIREs Energy Environ. 2014, 3, 424-473. [CrossRef]

3. Lu, W.; Lieber, C.M. Semiconductor nanowires. J. Phys. D Appl. Phys. 2006, 39, R387-R406. [CrossRef]

4. Duan, X.; Lieber, C.M. General Synthesis of Compound Semiconductor Nanowires. Adv. Mater. 2000, 12, 298-302. [CrossRef]

5. Owens, A.; Peacock, A. Compound semiconductor radiation detectors. Nucl. Instrum. Methods Phys. Res. Sect. A Accel. Spectrometers Detect. Assoc. Equip. 2004, 531, 18-37. [CrossRef]

6. Song, H.; Lee, S. Red light emitting solid state hybrid quantum dot-near-UV GaN LED devices. Nanotechnology 2007, 18, 255202. [CrossRef]

7. Ikawa, Y.; Lee, K.; Ao, J.-P.; Ohno, Y. Two-dimensional device simulation of AlGaN/GaN heterojunction FET side-gating effect. Jpn. J. Appl. Phys. 2014, 53, 114302. [CrossRef]

8. Podolska, A.; Seeber, R.M.; Mishra, U.K.; Pfleger, K.D.G.; Parish, G.; Nener, B.D. Detection of Biological Reactions by AlGaN/GaN Biosensor. In Proceedings of the COMMAD 2012, Melbourne, Australia, 12-14 December 2012; pp. 75-76. [CrossRef]

9. Khan, M.; Rao, M.; Li, Q. Recent Advances in Electrochemical Sensors for Detecting Toxic Gases: $\mathrm{NO}_{2}, \mathrm{SO}_{2}$ and $\mathrm{H}_{2}$ S. Sensors 2019, 19, 905. [CrossRef]

10. Prokopuk, N.; Son, K.-A.; George, T.; Moon, J.S. Development of GaN-Based Micro Chemical Sensor Nodes. In Proceedings of the IEEE Sensors 2005, Irvine, CA, USA, 30 October-3 November 2005; pp. $199-202$. [CrossRef]

11. Pearton, S.J.; Kang, B.S.; Kim, S.K.; Ren, F.X.; Gila, B.; Abernathy, C.R.; Lin, J.; Chu, G. GaN-based diodes and transistors for chemical, gas, biological and pressure sensing. J. Phys. Condens. Matter 2004, 16, R961-R994. [CrossRef]

12. Moses, P.G.; Miao, M.; Yan, Q.; van de Walle, C.G. Hybrid functional investigations of band gaps and band alignments for AlN, GaN, InN, and InGaN. J. Chem. Phys. 2011, 134, 084703. [CrossRef]

13. Schalwig, J.; Müller, G.; Eickhoff, M.; Ambacher, O.; Stutzmann, M. Group III-nitride-based gas sensors for combustion monitoring. Mater. Sci. Eng. B 2002, 93, 207-214. [CrossRef]

14. Eickhoff, M.; Schalwig, J.; Steinhoff, G.; Weidemann, O.; Görgens, L.; Neuberger, R.; Hermann, M.; Baur, B.; Müller, G.; Ambacher, O.; et al. Electronics and sensors based on pyroelectric AlGaN/GaN heterostructures-Part B: Sensor applications. Phys. Stat. Solidi (c) 2003, 6, 1908-1918. [CrossRef]

15. Nahhas, A.M. Review of GaN Nanostructured Based Devices. Am. J. Nanomater. 2018, 6, 1-14. [CrossRef]

16. Alreshaid, A.T.; Hester, J.G.; Su, W.; Fang, Y.; Tentzeris, M.M. Review-Ink-Jet Printed Wireless Liquid and Gas Sensors for IoT, SmartAg and Smart City Applications. J. Electrochem. Soc. 2018, 165, B407-B413. [CrossRef]

17. Thibaud, M.; Chi, H.; Zhou, W.; Piramuthu, S. Internet of Things (IoT) in high-risk Environment, Health and Safety (EHS) industries: A comprehensive review. Decis. Support Syst. 2018, 108, 79-95. [CrossRef]

18. Gomes, J.B.A.; Rodrigues, J.J.P.C.; Rabêlo, R.A.L.; Kumar, N.; Kozlov, S. IoT-Enabled Gas Sensors: Technologies, Applications, and Opportunities. JSAN 2019, 8, 57. [CrossRef]

19. Wang, Z.L. Chapter 10-Novel Nanostructures and Nanodevices of ZnO. In Zinc Oxide Bulk, Thin Films and Nanostructures; Jagadish, C., Pearton, S., Eds.; Elsevier Science Ltd.: Oxford, UK, 2006; pp. 339-370.

20. Rani, A.; DiCamillo, K.; Khan, M.A.H.; Paranjape, M.; Zaghloul, M.E. Tuning the Polarity of MoTe2 FETs by Varying the Channel Thickness for Gas-Sensing Applications. Sensors 2019, 19, 2551. [CrossRef]

21. Basu, P.B.S. Nanostructured Ceramic Materials for Chemical Sensors: Present Status and Future Prospects. Trans. Indian Ceram. Soc. 2010, 69, 1-23. [CrossRef]

22. Sun, Y.-F.; Liu, S.-B.; Meng, F.-L.; Liu, J.-Y.; Jin, Z.; Kong, L.-T.; Liu, J.-H. Metal Oxide Nanostructures and Their Gas Sensing Properties: A Review. Sensors 2012, 12, 2610-2631. [CrossRef] 
23. Sarf, F. Metal Oxide Gas Sensors by Nanostructure. In Gas Sensors; Khan, S.B., Asiri, A.M., Akhtar, K., Eds.; IntechOpen: London, UK, 2019. [CrossRef]

24. Kente, T.; Mhlanga, S.D. Gallium nitride nanostructures: Synthesis, characterization and applications. J. Cryst. Growth 2016, 444, 55-72. [CrossRef]

25. Kim, K.-S.; Chung, G.-S. Characterization of porous cubic silicon carbide deposited with $\mathrm{Pd}$ and $\mathrm{Pt}$ nanoparticles as a hydroge sensor. Sens. Actuators B Chem. 2011, 157, 482-487. [CrossRef]

26. Linke, S.; Dallmer, M.; Werner, R.; Moritz, W. Low energy hydrogen sensor. Int. J. Hydrogen Energy 2012, 37, 17523-17528. [CrossRef]

27. Kim, S.S.; Park, J.Y.; Choi, S.-W.; Kim, H.S.; Na, H.G.; Yang, J.C.; Lee, C.; Kim, H.W. Room temperature sensing properties of networked GaN nanowire sensors to hydrogen enhanced by the Ga2Pd5 nanodot functionalization. Int. J. Hydrogen Energy 2011, 36, 2313-2319. [CrossRef]

28. Shen, Y.; Yamazaki, T.; Liu, Z.; Meng, D.; Kikuta, T. Hydrogen sensors made of undoped and Pt-doped SnO2 nanowires. J. Alloys Compd. 2009, 488, L21-L25. [CrossRef]

29. Aluri, G.S.; Motayed, A.; Davydov, A.V.; Oleshko, V.P.; Bertness, K.A.; Sanford, N.A.; Mulpuri, R.V. Methanol, ethanol and hydrogen sensing using metal oxide and metal ( $\left.\mathrm{TiO}_{2}-\mathrm{Pt}\right)$ composite nanoclusters on GaN nanowires: A new route towards tailoring the selectivity of nanowire/nanocluster chemical sensors. Nanotechnology 2012, 23, 175501. [CrossRef]

30. Du, X.; Wang, Y.; Mu, Y.; Gui, L.; Wang, P.; Tang, Y. A New Highly Selective H2 Sensor Based on TiO2/PtO-Pt Dual-Layer Films. 10 August 2002. Available online: https://pubs.acs.org/doi/abs/10.1021/cm0201293 (accessed on 6 April 2019).

31. Abdullah, Q.N.; Yam, F.K.; Hassan, Z.; Bououdina, M. Hydrogen gas sensing performance of GaN nanowires-based sensor at low operating temperature. Sens. Actuators B Chem. 2014, 204, 497-506. [CrossRef]

32. Paul, S.; Helwig, A.; Müller, G.; Furtmayr, F.; Teubert, J.; Eickhoff, M. Opto-chemical sensor system for the detection of $\mathrm{H} 2$ and hydrocarbons based on InGaN/GaN nanowires. Sens. Actuators B Chem. 2012, 173, 120-126. [CrossRef]

33. Wright, J.S.; Lim, W.; Gila, B.P.; Pearton, S.J.; Johnson, J.L.; Ural, A.; Ren, F. Hydrogen sensing with Pt-functionalized GaN nanowires. Sens. Actuators B Chem. 2009, 140, 196-199. [CrossRef]

34. Park, S.; Kim, S.; Park, S.; Lee, S.; Lee, C. Room temperature hydrogen sensing performances of multiple networked GaN nanowire sensors codecorated with Au and Pt nanoparticles. J. Cent. South Univ. 2015, 22, 1614-1618. [CrossRef]

35. Sahoo, P.; Dhara, S.; Dash, S.; Amirthapandian, S.; Prasad, A.K.; Tyagi, A.K. Room temperature H2 sensing using functionalized GaN nanotubes with ultra low activation energy. Int. J. Hydrogen Energy 2013, 38, 3513-3520. [CrossRef]

36. Johnson, J.L.; Choi, Y.; Ural, A.; Lim, W.; Wright, J.S.; Gila, B.P.; Ren, F.; Pearton, S.J. Growth and Characterization of GaN Nanowires for Hydrogen Sensors. J. Electron. Mater. 2009, 38, 490-494. [CrossRef]

37. Zhong, A.; Sasaki, T.; Hane, K. Platinum/porous GaN nanonetwork metal-semiconductor Schottky diode for room temperature hydrogen sensor. Sens. Actuators A Phys. 2014, 209, 52-56. [CrossRef]

38. Chitara, B.; Late, D.J.; Krupanidhi, S.B.; Rao, C.N.R. Room-temperature gas sensors based on gallium nitride nanoparticles. Solid State Commun. 2010, 150, 2053-2056. [CrossRef]

39. Lim, W.; Wright, J.S.; Gila, B.P.; Johnson, J.L.; Ural, A.; Anderson, T.; Ren, F.; Pearton, S.J. Room temperature hydrogen detection using Pd-coated GaN nanowires. Appl. Phys. Lett. 2008, 93, 072109. [CrossRef]

40. Abdullahab, Q.N.; Ahmedb, A.R.; Alib, A.M.; Yama, F.K.; Hassana, Z.; Bououdinacd, M.; Almessiere, M.A. Growth and characterization of GaN nanostructures under various ammoniating time with fabricated Schottky gas sensor based on Si substrate. Superlattices Microstruct. 2018, 117, 92-104. [CrossRef]

41. Ramizy, A.; Hassan, Z.; Omar, K. Porous GaN on Si(111) and its application to hydrogen gas sensor. Sens. Actuators B Chem. 2011, 155, 699-708. [CrossRef]

42. Zhong, A.; Sasaki, T.; Hane, K. Comparative study of Schottky diode type hydrogen sensors based on a honeycomb GaN nanonetwork and on a planar GaN film. Int. J. Hydrogen Energy 2014, 39, 8564-8575. [CrossRef]

43. Bennett, I.L.; Cary, F.H.; Mitchell, G.L.; Cooper, M.N. Acute Methyl Alcohol Poisoning: A Review Based on Experiences in an Outbreak of 323 Cases. Medicine 1953, 32, 431. [CrossRef]

44. Ji, H.F.; Liu, W.K.; Li, S.; Li, Y.; Shi, Z.F.; Tian, Y.T.; Li, X.J. High-performance methanol sensor based on GaN nanostructures grown on silicon nanoporous pillar array. Sens. Actuators B Chem. 2017, 250, 518-524. [CrossRef] 
45. Luo, X.; Zheng, X.; Wang, D.; Zhang, Y.; Cheng, H.; Wang, X.; Zhuang, H.; Lou, Y. The ethanol-sensing properties of porous GaN nanofibers synthesized by electrospinning. Sens. Actuators B Chem. 2014, 202, 1010-1018. [CrossRef]

46. Wang, G.X.; Park, J.S.; Park, M.S.; Gou, X.L. Synthesis and high gas sensitivity of tin oxide nanotubes. Sens. Actuators B Chem. 2008, 131, 313-317. [CrossRef]

47. Bajpai, R.; Motayed, A.; Davydov, A.V.; Oleshko, V.P.; Aluri, G.S.; Bertness, K.A.; Rao, M.V.; Zaghloul, M. EUV-assisted alcohol sensing using $\mathrm{SnO} 2$ functionalized GaN nanowire devices. Sens. Actuators B Chem. 2012, 171-172, 499-507. [CrossRef]

48. Zhang, M.; Zhao, C.; Gong, H.; Niu, G.; Wang, F. High Sensitivity Gas Sensor Based on Porous GaN Nanorods with Excellent High-Temperature Stability. In Proceedings of the 2019 20th International Conference on Solid-State Sensors, Actuators and Microsystems \& Eurosensors XXXIII (TRANSDUCERS \& EUROSENSORS XXXIII), Berlin, Germany, 23-27 June 2019; pp. 1369-1372. [CrossRef]

49. Zhang, M.; Zhao, C.; Gong, H.; Niu, G.; Wang, F. Porous GaN Submicron Rods for Gas Sensor with High Sensitivity and Excellent Stability at High Temperature. ACS Appl. Mater. Interfaces 2019, 11, 33124-33131. [CrossRef] [PubMed]

50. Methane Gas Detection-Methane Gas Sensors. Available online: http://www.pem-tech.com/methanecombustible.html (accessed on 1 March 2020).

51. Patsha, A.; Sahoo, P.; Amirthapandian, S.; Prasad, A.K.; Das, A.; Tyagi, A.K.; Cotta, M.A.; Dhara, S. Localized Charge Transfer Process and Surface Band Bending in Methane Sensing by GaN Nanowires. J. Phys. Chem. C 2015, 119, 21251-21260. [CrossRef]

52. Batzill, M.; Diebold, U. The surface and materials science of tin oxide. Prog. Surf. Sci. 2005, 79, 47-154. [CrossRef]

53. Popa, V.; Tiginyanu, I.M.; Ursaki, V.V.; Volcius, O.; Morkoç, H.A. GaN-based two-sensor array for methane detection in an ethanol environment. Semicond. Sci. Technol. 2006, 21, 1518-1521. [CrossRef]

54. Dobrokhotov, V.; McIlroy, D.N.; Norton, M.G.; Abuzir, A.; Yeh, W.J. Principles and mechanisms of gas sensing by GaN nanowires functionalized with gold nanoparticles. J. Appl. Phys. 2006, 99, 104302. [CrossRef]

55. Aluri, G.S.; Motayed, A.; Bertness, K.; Sanford, N.; Oleshko, V.; Davydov, A.; Rao, M.V. Highly selective $\mathrm{GaN}$-nanowire/ $\mathrm{TiO}_{2}$-nanocluster hybrid sensors for detection of benzene and related environment pollutants. Nanotechnology 2011, 22, 295503. [CrossRef]

56. Aluri, G.S.; Motayed, A.; Davydov, A.V.; Oleshko, V.P.; Bertness, K.A.; Rao, M.V. Nitro-Aromatic Explosive Sensing Using GaN Nanowire-Titania Nanocluster Hybrids. IEEE Sens. J. 2013, 13, 1883-1888. [CrossRef]

57. Reddeppa, M.; Park, B.-G.; Chinh, N.D.; Kim, D.; Oh, J.-E.; Kim, T.G.; Kim, M.-D. A novel low-temperature resistive NO gas sensor based on InGaN/GaN multi-quantum well-embedded p-i-n GaN nanorods. Dalton Trans. 2019, 48, 1367-1375. [CrossRef]

58. Chandran, B.; Janakiraman, K. New Disposable Nitric Oxide Sensor Fabrication Using GaN Nanowires. ACS Omega 2019, 4, 17171-17176. [CrossRef] [PubMed]

59. Khan, M.A.H.; Thomson, B.; Debnath, R.; Rani, A.; Motayed, A.; Rao, M.V. Reliable anatase-titania nanoclusters functionalized $\mathrm{GaN}$ sensor devices for $\mathrm{UV}$ assisted $\mathrm{NO}_{2}$ gas-sensing in ppb level. Nanotechnology 2020, 31, 155504. [CrossRef] [PubMed]

60. Shi, C.; Rani, A.; Thomson, B.; Debnath, R.; Motayed, A.; Yoannou, D.E.; Li, Q. High-performance room-temperature $\mathrm{TiO}_{2}$-functionalized $\mathrm{GaN}$ nanowire gas sensors. Appl. Phys. Lett. 2019, 115, 121602. [CrossRef]

61. Maier, K.; Helwig, A.; Müller, G.; Becker, P.; Hille, P.; Schörmann, J.; Teubert, J.; Eickhoff, M. Detection of oxidising gases using an optochemical sensor system based on $\mathrm{GaN} / \mathrm{InGaN}$ nanowires. Sens. Actuators B Chem. 2014, 197, 87-94. [CrossRef]

62. Sim, J.; Kim, K.; Song, S.; Kim, J. Suspended GaN nanowires as $\mathrm{NO}_{2}$ sensor for high temperature applications. Analyst 2013, 138, 2432. [CrossRef]

63. Khan, M.A.H.; Thomson, B.; Yu, J.; Debnath, R.; Motayed, A.; Rao, M.V. Scalable metal oxide functionalized GaN nanowire for precise SO2 detection. Sens. Actuators B Chem. 2020, 318, 128223. [CrossRef]

64. Thomson, B.; Shi, C.; Rani, A.; Debnath, R.; Motayed, A. Low-power, Chip-Scale, Carbon Dioxide Gas Sensors for Spacesuit Monitoring. In Proceedings of the 48th International Conference on Environmental Systems, Albuquerque, NM, USA, 8-12 July 2018.

65. Ke, M.-T.; Lee, M.-T.; Lee, C.-Y.; Fu, L.-M. A MEMS-based Benzene Gas Sensor with a Self-heating $\mathrm{WO}_{3}$ Sensing Layer. Sensors 2009, 9, 2895-2906. [CrossRef] 
66. Michel, A.P.M.; Kapit, J. Deep Ultraviolet Light Emitting Diode (LED)-Based Sensing of Sulfur Dioxide. Appl. Spectrosc. 2017, 71, 996-1003. [CrossRef]

67. Chang, J.F.; Kuo, H.H.; Leu, I.C.; Hon, M.H. The effects of thickness and operation temperature on $\mathrm{ZnO}: \mathrm{Al}$ thin film CO gas sensor. Sens. Actuators B Chem. 2002, 84, 258-264. [CrossRef]

68. Bajpai, R.; Motayed, A.; Davydov, A.V.; Bertness, K.A.; Zaghloul, M.E. UV-Assisted Alcohol Sensing With Zinc Oxide-Functionalized Gallium Nitride Nanowires. IEEE Electron. Device Lett. 2012, 33, 1075-1077. [CrossRef]

69. Fan, S.-W.; Srivastava, A.K.; Dravid, V.P. UV-activated room-temperature gas sensing mechanism of polycrystalline ZnO. Appl. Phys. Lett. 2009, 95, 142106. [CrossRef]

70. Costello, B.P.J.D.; Ewen, R.J.; Ratcliffe, N.M.; Richards, M. Highly sensitive room temperature sensors based on the UV-LED activation of zinc oxide nanoparticles. Sens. Actuators B Chem. 2008, 134, 945-952. [CrossRef]

71. Khan, M.A.H.; Thomson, B.; Debnath, R.; Motayed, A.; Rao, M.V. Nanowire-Based Sensor Array for Detection of Cross-Sensitive Gases Using PCA and Machine Learning Algorithms. IEEE Sens. J. 2020, 20, 6020-6028. [CrossRef]

72. Nakata, S.; Akakabe, S.; Nakasuji, M.; Yoshikawa, K. Gas Sensing Based on a Nonlinear Response: Discrimination between Hydrocarbons and Quantification of Individual Components in a Gas Mixture. Anal. Chem. 1996, 68, 2067-2072. [CrossRef]

73. Khan, M.A.H.; Motayed, A.; Rao, M.V. Identification and Quantification of Gases and Their Mixtures Using GaN Sensor Array and Artificial Neural Network. ECS J. 2020. under review.

74. Yong, Y.; Cui, H.; Zhou, Q.; Su, X.; Kuang, Y.; Li, X. Adsorption of gas molecules on a graphitic GaN sheet and its implications for molecule sensors. RSC Adv. 2017, 7, 51027-51035. [CrossRef]

75. Yong, Y.; Su, X.; Cui, H.; Zhou, Q.; Kuang, Y.; Li, X. Two-Dimensional Tetragonal GaN as Potential Molecule Sensors for $\mathrm{NO}_{\text {and }} \mathrm{NO}_{2}$ Detection: A First-Principle Study. ACS Omega 2017, 2, 8888-8895. [CrossRef] [PubMed]

76. Abdulsattar, M.A. GaN wurtzite nanocrystals approached using wurtzoids structures and their use as a hydrogen sensor: A DFT study. Superlattices Microstruct. 2016, 93, 163-170. [CrossRef]

77. Khan, M.A.H.; Thomson, B.; Motayed, A.; Li, Q.; Rao, M.V. Functionalization of GaN Nanowire Sensors with Metal Oxides: An Experimental and DFT Investigation. IEEE Sens. J. 2020, 99, 1. [CrossRef]

78. Khan, M.A.H.; Thomson, B.; Motayed, A.; Li, Q.; Rao, M.V. Metal-oxide/GaN based $\mathrm{NO}_{2}$ Gas detection at room temperature: An experimental and density functional theory investigation. SPIE Defence commer. Sens. 2020, 11389, 103. [CrossRef]

79. Wang, C.; Yin, L.; Zhang, L.; Xiang, D.; Gao, R. Metal Oxide Gas Sensors: Sensitivity and Influencing Factors. Sensors 2010, 10, 2088-2106. [CrossRef] [PubMed]

80. Huang, J.-R.; Hsu, W.-C.; Chen, H.-I.; Liu, W.-C. Comparative study of hydrogen sensing characteristics of a Pd/GaN Schottky diode in air and N2 atmospheres. Sens. Actuators B Chem. 2007, 123, 1040-1048. [CrossRef]

81. Zhang, D.; Wu, J.; Li, P.; Cao, Y. Room-temperature $\mathrm{SO}_{2}$ gas-sensing properties based on a metal-doped $\mathrm{MoS}_{2}$ nanoflower: An experimental and density functional theory investigation. J. Mater. Chem. 2017, 5, 20666-20677. [CrossRef]

82. Potyrailo, R.A. Multivariable Sensors for Ubiquitous Monitoring of Gases in the Era of Internet of Things and Industrial Internet. Chem. Rev. 2016, 116, 11877-11923. [CrossRef] [PubMed]

83. Lien, D.-H.; Hsiao, Y.-H.; Yang, S.-G.; Tsai, M.-L.; Wei, T.-C.; Lee, S.-C.; He, J.-H. Harsh photovoltaics using InGaN/GaN multiple quantum well schemes. Nano Energy 2015, 11, 104-109. [CrossRef]

84. GaN Based Hydrogen Sensor in Humid Ambient. Meet. Abstr. 2017, 77, 6. [CrossRef]

85. Kamarudin, K.; Bennetts, V.H.; Mamduh, S.M.; Visvanathan, R.; Yeon, A.S.A.; Shakaff, A.Y.M.; Zakaria, A.; Abdullah, A.H.; Kamarudin, L.M. Cross-sensitivity of metal oxide gas sensor to ambient temperature and humidity: Effects on gas distribution mapping. AIP Conf. Proc. 2017, 1808, 20025. [CrossRef]

86. Chatterjee, S.G.; Chatterjee, S.; Ray, A.K.; Chakraborty, A.K. Graphene-metal oxide nanohybrids for toxic gas sensor: A review. Sens. Actuators B Chem. 2015, 221, 1170-1181. [CrossRef]

87. rsan, N.B.; Weimar, U. Understanding the fundamental principles of metal oxide based gas sensors; the example of $\mathrm{CO}$ sensing with $\mathrm{SnO}_{2}$ sensors in the presence of humidity. J. Phys. Condens. Matter 2003, 15, R813-R839. [CrossRef]

88. Albert, K.J.; Lewis, N.S.; Schauer, C.L.; Sotzing, G.A.; Stitzel, S.E.; Vaid, T.P.; Walt, D.R. Cross-Reactive Chemical Sensor Arrays. Chem. Rev. 2000, 100, 2595-2626. [CrossRef] 
89. Ashokkumar, M.; Thirumurugan, T. Integrated IOT based design and Android operated Multi-purpose Field Surveillance Robot for Military Use. In Proceedings of the International Conference for Phoenixes on Emerging Current Trends in Engineering and Management (PECTEAM 2018), Chennai, India, 9-10 February 2018. [CrossRef]

90. Shu, L.; Mukherjee, M.; Wu, X. Toxic gas boundary area detection in large-scale petrochemical plants with industrial wireless sensor networks. IEEE Commun. Mag. 2016, 54, 22-28. [CrossRef]

91. Rushikesh, R.; Sivappagari, C.M.R. Development of IoT based vehicular pollution monitoring system. In Proceedings of the 2015 International Conference on Green Computing and Internet of Things (ICGCIoT), Greater Noida, Delhi, India, 8-10 October 2015; pp. 779-783. [CrossRef]

C) 2020 by the authors. Licensee MDPI, Basel, Switzerland. This article is an open access article distributed under the terms and conditions of the Creative Commons Attribution (CC BY) license (http://creativecommons.org/licenses/by/4.0/). 